Phonological Data and Analysis Volume 2, Article 4: 1-28 (2020)

https://doi.org/10.3765/pda.v2art4.3

Received 17 May 2018; revised 10 January 2019, 31 July 2019; accepted 08 March 2020. (C) 2020 Christian DiCanio et al. Published by the Linguistic Society of America with permission of the authors under a CC BY 3.0 license.

\title{
Glottal toggling in Itunyoso Triqui
}

\author{
Christian DiCanio ${ }^{a}$, Basileo Martínez Cruz ${ }^{b}$, Benigno Cruz Martínez ${ }^{b}$ \& Wilberto \\ Martínez Cruz ${ }^{\mathrm{b} *}$ \\ aUniversity at Buffalo - cdicanio@buffalo.edu \\ bProyecto de documentación de la lengua triqui de San Martín Itunyoso - basi.mtz@outlook.es, \\ cruz1302@hotmail.com, wilber.smi@gmail.com
}

Itunyoso Triqui (Oto-Manguean: Mexico) possesses several unique morphological derivations, each of which is typified by a toggling of glottal features at the right edge of the root. Root-final coda $/ \mathrm{h} /$ is deleted if it is present on uninflected stems, but inserted if it is absent. This process, traditionally known as a morphophonological exchange rule (c.f. Baerman 2007; de Lacy 2012; Wunderlich 2012), is regular and productive in the language. Moreover, it is the primary exponent of the first person singular, the topical third person, and nominal quantifier morphemes, while tonal alternations are secondary, morpheme-specific exponents. The current paper both provides the first comprehensive description of these patterns in Itunyoso Triqui and argues two theoretical points. First, Triqui glottal toggling involves a morphophonological exchange mapping $(/ \alpha / \rightarrow[\beta] ; / \beta / \rightarrow[\alpha])$ which, in coordination with syllable well-formedness conditions, produces a toggling pattern. Second, exchange mappings or rules like the Triqui toggle pose unique problems for parallelist approaches to Optimality Theory but not to serialist approaches which permit intermediate stages of representation, a finding that accords well with the necessity for multiple strata in Triqui word formation.

Keywords: Oto-Manguean; tone; glottalization; morphophonology; clitics

\section{Introduction}

Oto-Manguean languages are known for possessing both complex tonal inventories (DiCanio \& Bennett 2020; Pike 1948) and a complex set of laryngeal contrasts (phonation type and glottal consonants) (Macaulay \& Salmons 1995; Pankratz \& Pike 1967; Pike 1948; Silverman 1997). Each of these features is utilized extensively in Oto-Manguean phonological inventories for marking lexical contrast. However, the heavy use of tone in the inflectional morphology of these languages represents an additional layer of phonological complexity. In certain systems, tone and glottal features combine to create a large set of unique inflectional classes, as in Amuzgo (Kim 2016). In other systems, specific and regular tonal alternations are used to mark verbal inflection and person, as in Yoloxóchitl Mixtec (Palancar, Amith \& Castillo García 2016). In Itunyoso Triqui, the language investigated here, segmental changes are one of the regular exponents for a set of different morphological alternations, while the concomitant tonal changes are more complex and partially irregular; they are regular for certain underlying root tonal contours but require positing lexical classes for others. The regular segmental alternation in Itunyoso Triqui for the first person singular, third person topic,

* This work was supported by NSF Grant \#1603323 (DiCanio, PI) at the University at Buffalo. We would like to acknowledge the helpful comments/suggestions that Karen Michelson, Paul de Lacy, Ryan Bennett, Megan Crowhurst, Indranil Dutta, and an anonymous reviewer made on versions of this paper. 
and an adjectival $\rightarrow$ nominal quantifier derivation involves a toggling of glottal features. If a root ends with a coda $/ \mathrm{h} /$, it is deleted. If coda $/ \mathrm{h} /$ is absent, it is inserted.

Feature toggling at the interface of morphology and phonology has been typically regarded as a type of morphophonological exchange rule. Rules such as these, where morphological exponents exchange in the same morphological context $(/ \alpha / \rightarrow[\beta]$ and $/ \beta / \rightarrow[\alpha]$ ), are considered to be cross-linguistically rare (Wunderlich 2012). Existing prototypical examples have been reanalyzed as separate types of processes for each pathway in the alternation, i.e. $/ \alpha / \rightarrow[\beta]$ reflects a distinct operation from $/ \beta / \rightarrow[\alpha]$. Along these grounds, the most well-discussed case, pluralization in Dholuo, is argued to not be an example of a true exchange rule at all (de Lacy 2012). de Lacy argues that the phonological context for producing the devoicing alternation is distinct from that which produces voicing. Other cases are argued to reflect distinct morphosyntactic operations (Wunderlich 2012).

The pattern in Itunyoso Triqui is neither marginal within the set of exponents encoding various morphological alternations, nor is there any morphosyntactic or semantic distinction between roots which possess a syllable-final coda $/ \mathrm{h} /$ and roots which do not. As such, along the empirical grounds discussed in de Lacy (2012), it is a morphophonological exchange rule. The goals of the current paper are to both describe the toggling morphophonology in Itunyoso Triqui and analyze the data in relation to previous work on morphophonological exchange rules. In $§ 1.1$, we provide a brief overview of previous work on morphophonological exchange rules and present a set of criteria for empirically defining them. In $\S 2$, we briefly describe the phonological system of Itunyoso Triqui and provide an in-depth description of the toggling process in each of the morphemes where it is an exponent. In $\S 3.1$, we review the empirical evidence presented in relation to the definitional criteria developed in $\S 1.1$. In $\S 3.2$, we examine how the Triqui toggling process may be formalized and present an analysis of the glottal alternations as morphophonological exchange mappings within a serialist approach. We conclude the paper discussing the types of tools that must be necessary within a phonological grammar to account for such processes.

\subsection{Morphophonological exchange rules}

A morphophonological exchange rule, or toggle, is defined as an alternation where $/ \alpha / \rightarrow[\beta]$ and $/ \beta / \rightarrow[\alpha]$ in the same morphological and phonological context. This pattern is a sub-type of a morphological exchange rule (c.f. Baerman 2007), though morphological exchange rules need not include phonological rules at the boundary between morphemes. Baerman (2007) calls such rules morphological reversals. The morphological exponents of an exchange rule may be arbitrarily connected and not phonologically-derivable, e.g. $/ 1 / \rightarrow$ [p] and $/ \mathrm{p} / \rightarrow$ [1], though morphophonological exchange rules involve specific phonological properties, such as place of articulation, e.g. [CORONAL] $\rightarrow$ [DORSAL] and [DORSAL] $\rightarrow$ [CORONAL]. A classic case of a morphophonological exchange rule is the case of the Dholuo plural (Tucker 1994), shown in Table 1.

Table 1: Dholuo plural data, from de Lacy $(2012,121-122)$.

\begin{tabular}{|c|c|c|c|c|c|}
\hline Singular & Plural & Root gloss & Singular & Plural & Root gloss \\
\hline a. alap & ælæbe & 'open space' & d. kitæbu & kitepe & 'book' \\
\hline b. got & gode & 'hill' & e. $\mathrm{k} \varepsilon \mathrm{d} \varepsilon$ & kete & 'twig' \\
\hline c. agoko & $\operatorname{ag} \supset g \varepsilon$ & 'chest' & f. higa & hike & 'year' \\
\hline
\end{tabular}

The forms on the left in Table 1 show an alternation where the final voiceless consonant is voiced in the plural. The forms on the right show an alternation where the medial voiced consonants are voiceless in the plural. At first glance, this appears to be a morpho-phonological exchange rule, i.e. [ $\alpha$ VOICE $] \rightarrow[-\alpha$ VOICE]. Yet, on further inspection, de Lacy (2012) argues that the input forms for the voicing alternation systematically differ in phonological shape.

De Lacy makes the following arguments in relation to the Dholuo voicing alternation. First, there exist 
words for which no voicing alternation occurs (p.123). The lack of an alternation here suggests that there is something relevant about the input requirements for the alternation to occur. Re-examining the existing data, he argues that no voicing alternation occurs with consonant-final roots, shown in (a) and (b) in Table 1. Rather, the voicing of the consonant is maintained in the plural, while root-final devoicing occurs with the singular. Vowel-final roots, shown in (d)-(f), undergo a process whereby the final non-sonoront consonant is devoiced in the plural. ${ }^{1}$ Second, if one considers this solely as a process of devoicing in vowel-final roots, the analysis fits with the range of other morphophonological alternations in the language. Both qualitative stems and verbal nouns involve the same stem formation process in Dholuo: devoicing of the last obstruent in V-final roots. In fact, many morphological processes in Dholuo involve a mutation of this particular consonant (desonorization, devoicing, etc). de Lacy concludes that Dholuo pluralization is not an example of a morphophonological exchange rule.

Given that Dholuo is a well-cited example of an exchange rule, de Lacy calls into question (a) whether such rules exist as productive processes in human languages and (b) whether a phonological grammar should possess the tools necessary to generate them, in particular anti-faithfulness constraints (Alderete 2001). Reexamining additional data from Kumeyaay (Miller 2001) and Shilluk (Westermann 1912), he argues that apparent morphophonological exchange rules in these languages (short vowels become long and vice versa) involve different morphological categories. The process of shortening long vowels is uncommon $/ \mathrm{marked}$ and there exist a number of additional morphological exponents marking the alternation. Thus, he argues, the morpho-syntactic category which undergoes a vowel shortening rule must be distinct from the category which undergoes a vowel lengthening rule. This is essentially the same argument that Wunderlich (2012) makes in relation to morphological exchange rules; that each pathway of the exchange rule reflects a different morphosyntactic operation.

The arguments that de Lacy and Wunderlich use to reanalyze morphophonological exchange rules may be treated as a set of definitional criteria. If an alternation is to be considered a true morphophonological exchange rule, it must satisfy the following:

(1) Productivity: the alternation must not apply to a limited, closed set of roots in the language.

(2) Dominance: the alternation must be the dominant morphological exponent for the morpheme in question. $^{2}$

(3) Morphosyntactic uniformity: all roots undergoing the alternation must belong to the same morphosyntactic category.

Crucially, the third criterion above, morphosyntactic uniformity must be motivated on morphosyntactic grounds. That is, one cannot assume that a root which undergoes an alternation $/ \alpha / \rightarrow[\beta]$ must belong to a different morphosyntactic category than a root which undergoes an alternation $/ \beta / \rightarrow[\alpha]$ simply because each undergoes a different alternation. Such reasoning is circular. The data from Itunyoso Triqui is analyzed in the current paper with particular attention to each of these criteria.

\section{Itunyoso Triqui glottal toggling}

\subsection{Language background and Methods}

Itunyoso Triqui (English [,itun'jorsor 'txiki], Spanish ['triki ðe ,itun'joso]) is spoken by approximately 2,500 people and is one of three Triqui dialects spoken in Oaxaca, Mexico. The others are Copala Triqui

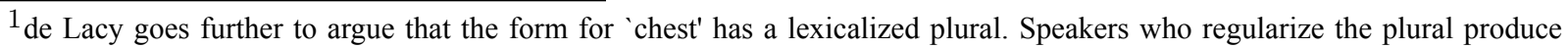
lagoke/ (de Lacy 2012, 124).

${ }^{2}$ Though see Inkelas (2011) for a discussion regarding why this criterion is more generally problematic in cases of multiple exponence.
} 
(Broadwell \& Clemens 2017; Hollenbach 1984, 2004, 2007) and Chicahuaxtla Triqui (Elliott, Edmondson \& Sandoval Cruz 2016; Hernández Mendoza 2017; Longacre 1952, 1959). All of the findings presented here come from original fieldwork carried out by the first author in the town of San Martín Itunyoso, Oaxaca and Tlaxiaco, Oaxaca from 2004 - 2017.

From 2015 - 2017, a database of paradigms was compiled and corrected, consisting of all of the morphological alternations for 507 Itunyoso Triqui stems. An incomplete database of paradigms was originally compiled from fieldwork elicitation sessions and text transcription/translation sessions spanning 2004-2017 where the first author worked closely with eight native speakers, ranging in age from 19 - 55 years old. Missing cells in the paradigm database were filled in during fieldwork with a male speaker (age 21) over the span of two months, starting in 2015. This database was subsequently checked over by the first author and an older male speaker (age 32) in 2016 and again by the first speaker in 2017. All of the speakers were fluent in Itunyoso Triqui as their first language and use the language in daily communication with their families and with other members of the Triqui community, where it is the main language of communication. ${ }^{3}$

Though the first author worked mainly with male speakers and these forms come from elicited speech, it is important to note that (a) there are no gender differences pertaining to the application/use of clitic morphology and (b) toggling morphology does not vary with speech style. Moreover, the authors have transcribed 20 hours of narrative recordings in the language, produced by 30 different speakers (a mixture of ages and genders). Inflected forms used in these recordings have all extremely closely corresponded with the forms in the database of paradigms. Where mismatches have been observed, these tend to reflect small errors in tonal transcription, e.g. tone level /2/ instead of tone level /1/, but have never reflected an error in the application of the toggling process.

Both the first author/fieldworker and these speakers were deeply familiar with the morphology of Itunyoso Triqui and the team sought to include as many unique stems as possible. Two lists of 234 nouns and 273 predicates (verbs and adjectival predicates) were compiled. These were compiled separately since verbal paradigms needed to include aspectual marking and were more complex than the nominal paradigms. Unpossessable, abstract nouns, many adverbs, and discourse particles were excluded from the list of possible stems since none of these categories can be marked for person. Additional forms and data were taken from an Itunyoso Triqui lexicon of 3,318 words (DiCanio et al., no date).

\subsection{Phonological preliminaries}

The phonology and phonetics of Itunyoso Triqui are previously described in DiCanio (2008, 2010, 2012a,b, 2014, 2016). The generalizations regarding the phonological structure of Triqui here are specific to the uninflected morphological stem. There are nine contrastive tones in uninflected words in the language, though additional tones occur in certain inflected forms. Stress is fixed, non-contrastive, and obligatory in stem-final syllables. Stress is realized by both increased phonetic duration in stem-final syllables in both non-utterance final and in utterance-final positions (DiCanio 2010; DiCanio \& Hatcher 2018) and by a large number of distributional asymmetries in the phonological system (DiCanio 2008) (i.e., maximal contrast occurs on the stem-final syllable). In other words, stem-final lengthening is consistently produced regardless of where the stem appears in an utterance -- it is not restricted to utterance-final position. ${ }^{4}$

The stress-based lengthening is also consistent with a bimoraic structure to stem-final syllables, meaning that one observes either final syllables of the shape CV:, CVh or CV?, but all non-final syllables are monomoraic and open, CV. Final syllables with codas always have short vowels while final syllables without a coda always have long vowels. These characteristics of the stress system are typical of other Triqui varieties as well (Hernández Mendoza 2017; Hollenbach 1984).

\footnotetext{
${ }^{3}$ Bilingualism in the Itunyoso Triqui community is sequential bilingualism. Children often do not speak Spanish until they attend school at age 4 or 5 , where Spanish is the main language of instruction.

${ }^{4}$ For a recent discussion of the importance of this methodological point, see Gordon \& Roettger (2017).
} 
The phonemic consonant and vowel inventories of Itunyoso Triqui are given in Tables 2 and 3 . The segmental inventory is described in substantial detail in DiCanio (2008) and DiCanio (2010). Two observations are pertinent to the present paper, however. First, the contrast between singleton and geminate consonants occurs only the onset of monosyllabic stems (see also DiCanio 2012b) and reflects a historical process of compensatory lengthening where pretonic */(j)V/- syllables were lost, i.e., Copala Triqui $/ \mathrm{ju} \mathrm{Se}^{3} / \mathrm{vs}$. Itunyoso Triqui $/ \beta \beta \mathrm{e}^{32}$ / 'maguey cactus'. In polysyllabic words only singleton consonants occur. Second, there is a process of regressive nasal harmony where a nasal feature spreads leftward until blocked by an obstruent or sonorant nasal (see also DiCanio 2008). For instance, $/ \mathrm{ki}^{33} \mathrm{ja} \mathrm{f}^{3} / \rightarrow\left[\mathrm{ki}{ }^{32} \tilde{\mathrm{j}} \tilde{\mathrm{a}} \mathrm{h}^{3}\right]$ 'party, festival' but $/ \mathrm{ta}^{1} \mathrm{ma} \tilde{a}^{3} / \rightarrow$ $\left[\mathrm{ta}^{1} \mathrm{~m} \tilde{\tilde{O}}^{3}\right]$ 'beetle, bug.' Within the current paper, geminate consonants are transcribed as doubled consonants and, with the exception of V?V sequences, roots are transcribed without the application of nasal harmony.

Table 2: Itunyoso Triqui Consonant Inventory

\begin{tabular}{|c|c|c|c|c|c|c|c|c|c|}
\hline & Bilabial & Dental & Alveolar & Post-alveolar & $\begin{array}{l}\text { Palatal } \\
\end{array}$ & Retroflex & Velar & Labiovelar & Glottal \\
\hline $\begin{array}{l}\text { Stops } \\
\text { Pre-Nasalized } \\
\text { Glottalized }\end{array}$ & $\mathrm{p}$ & $t, t t$ & $\begin{array}{l}{ }^{n} \mathrm{~d} \\
{ }^{2 n}{ }_{\mathrm{d}}\end{array}$ & & & & $\begin{array}{l}\mathrm{k}, \mathrm{kk} \\
\mathrm{y}_{\mathrm{g}} \\
\mathrm{P}_{\mathrm{g}}\end{array}$ & $\begin{array}{c}\text { kw, kkw } \\
{ }^{\mathrm{n}} \mathrm{g}^{\mathrm{w}}\end{array}$ & ? \\
\hline Affricates & & & & $\mathrm{t} \int \mathrm{tt} \int$ & & ts, tts & & & \\
\hline $\begin{array}{l}\text { Nasals } \\
\text { Glottalized } \\
\text { Pre-Stopped }\end{array}$ & $\begin{array}{c}\mathrm{m}, \mathrm{mm} \\
{ }^{?} \mathrm{~m}\end{array}$ & & $\begin{array}{c}\mathrm{n}, \mathrm{nn} \\
{ }^{\mathrm{P}} \mathrm{n}\end{array}$ & & ${ }^{c} n$ & & & & \\
\hline Fricatives & & $\mathrm{s}$ & & $\int$ & & & & & fi \\
\hline $\begin{array}{l}\text { Approximants } \\
\text { Glottalized }\end{array}$ & $\begin{array}{c}\beta, \beta \beta \\
{ }^{3} \beta\end{array}$ & & $\begin{array}{c}1,11 \\
{ }^{1} 1\end{array}$ & & $\begin{array}{l}\mathrm{j}, \mathrm{jj} \\
\mathrm{P}_{\mathrm{j}}\end{array}$ & & & & \\
\hline $\begin{array}{l}\text { Trill } \\
\text { Glottalized }\end{array}$ & & & $\begin{array}{l}\mathrm{r} \\
{ }_{\mathrm{r}} \mathrm{r}\end{array}$ & & & & & & \\
\hline
\end{tabular}

Itunyoso Triqui has an inventory of five oral vowels and three nasal vowels. High vowels $(/ \mathrm{i}, \mathrm{u} /)$ following a nasal consonant (/n, nn, m, mm, Pn, $\left.\mathrm{Pm},{ }^{\mathrm{c}} \mathrm{n} /\right)$ are obligatorily nasalized, e.g. / $\mathrm{nnin} \mathrm{h}^{45} /$ `corn', but non-high vowels following a nasal consonant are not, e.g. $/ \mathrm{nne}^{3} /$ 'plough.' There is a contrast between the vowels /a/ and /â/ after nasal consonants, e.g. $/ \mathrm{na}^{4} /$ 'the past' vs. $/ \mathrm{na}^{4} /$ 'sunbeam.' More details regarding vowel nasalization in the language are found in DiCanio $(2008,2010)$.

Table 3: Itunyoso Triqui Vowel Inventory

\begin{tabular}{|l||c|c|c|}
\hline & Front & Central & Back \\
\hline Close & $\mathrm{i}, \tilde{\mathrm{i}}$ & & $\mathrm{u}, \tilde{\mathrm{u}}$ \\
\hline Close-Mid & $\mathrm{e}$ & $\tilde{\partial}$ & $\mathrm{o}$ \\
\hline Open & & $\mathrm{a}$ & \\
\hline
\end{tabular}

The distribution of tone in relation to coda glottal consonants is particularly pertinent for the current paper. ${ }^{5}$ Certain distributional restrictions occur with codas $/ \mathrm{h}, ? /$, shown in Table 4 . Contour tones freely surface on final open syllables, though tone $/ 45 /$ surfaces only with a coda /h/. There are no non-glottal codas in Itunyoso Triqui and like many of the phonological contrasts, glottal codas occur only in stemfinal position. /h/ only surfaces as a coda, but glottal stops may also surface as onsets in disyllabic /V.?V:/ sequences, e.g. $/ \mathrm{ja}^{3} \mathrm{~Pa}^{3} /$ 'brush.' Note that such sequences are not monosyllabic rearticulated vowels, but disyllabic sequences (c.f. DiCanio 2008). Only level tones may surface on syllables with a / $/$ / coda.

\footnotetext{
${ }^{5}$ Here and elsewhere, /5/ reflects the highest tone and /1/ the lowest. See DiCanio (2012a) for a thorough phonetic description of the tonal system.
} 
Table 4: The distribution of Itunyoso Triqui tones in relation to glottal consonants

\begin{tabular}{|c|c|c|c|c|c|c|c|c|}
\hline Tone & \multicolumn{2}{|c|}{ Open $\sigma$} & \multicolumn{2}{|c|}{ Coda $/ \mathrm{h} /$} & \multicolumn{2}{|c|}{ Coda / $/ \mathrm{T}$} & \multicolumn{2}{|c|}{ /VPV(f)/ } \\
\hline$/ 4 /$ & $\beta \beta \mathrm{e}^{4}$ & 'hair' & yã $h^{4}$ & 'dirt' & t $\int i P^{4}$ & 'our ancestor' & rã $\tilde{a}^{4} \mathrm{a} \tilde{h}^{4}$ & 'to dance' \\
\hline$/ 3 /$ & nne: ${ }^{3}$ & plough & yã $h^{3}$ & 'paper' & $\operatorname{tsip}^{3}$ & 'pulque' & nã $\tilde{a}^{3}$ ã ${ }^{3}$ & 'limestone' \\
\hline$/ 2 /$ & nne: ${ }^{2}$ & 'to lie' & nã $\AA^{2}$ & 'again' & $\operatorname{tt} \int i i^{2}$ & ${ }^{\prime} 10^{\prime}$ & $\mathrm{ta}^{2} \mathrm{Pah}^{2}$ & 'some, half' \\
\hline$/ 1 /$ & nne: $^{1}$ & 'naked' & kãh ${ }^{1}$ & 'naked' & $\mathrm{t} \int \mathrm{i} \mathrm{P}^{1}$ & `sweet' & na $^{1} \mathrm{Paf}^{1}$ & 'shame' \\
\hline /45/ & & & nã ${ }^{45}$ & 'to wash' & & & nã $\tilde{a}^{3} \tilde{a}^{45}$ & 'I return' \\
\hline$/ 13 /$ & $\beta \beta \mathrm{i}^{13}$ & 'two of them' & nã ${ }^{13}$ & 'this (one)' & & & kã $\tilde{l}^{1} \tilde{a}^{3}$ & 'four of them' \\
\hline /43/ & $t \int e^{43}$ & 'my father' & nnã ${ }^{43}$ & 'mother! (voc.)' & & & $\mathrm{ko}^{4}$ Po: $^{43}$ & 'to drink' \\
\hline $\mid 32 /$ & nne: ${ }^{32}$ & 'water' & nnã ${ }^{32}$ & 'cigarette' & & & sã $\tilde{a}^{3} \mathrm{a} \mathrm{h}^{2}$ & 'money' \\
\hline /31/ & nne: $:^{31}$ & 'meat' & & & & & kã $\tilde{a}^{3} \tilde{a}^{1}$ & 'wind, breath' \\
\hline
\end{tabular}

\subsubsection{Tonal distribution and autosegmental rules}

The patterns of glottal toggling in Itunyoso Triqui covary with tonal changes on stems. Thus, the tonotactic patterns and tonal constraints with respect to word size are necessary preliminaries for our understanding of how toggling morphology interacts with Itunyoso Triqui words. Monosyllabic roots comprise $27 \%$ of monomorphemic entries in the Itunyoso Triqui lexicon, while polysyllabic roots comprise $73 \%$ (63\% disyllabic, $10 \%$ trisyllabic).${ }^{6}$ The influence of stress on tone distribution is seen in disyllabic words, shown in Table 5. We observe that contour tones only surface in final, stressed syllables and the tonal contrasts in non-final, unstressed syllables are limited. For instance, tones $/ 4 /$ and $/ 43 /$ may only be preceded by tones $/ 3 /$ or $/ 4 /$. Tones $/ 2 /$ and $/ 32 /$ may only be preceded by tones $/ 2 /$ or $/ 3 /$. Tone $/ 1 /$ may be preceded only by tones $/ 3 /$ or $/ 1 /$.

Table 5: Tonal patterns on disyllabic words

\begin{tabular}{|c|c|c|c|c|c|c|}
\hline & \multicolumn{2}{|c|}{ Open $\sigma$} & \multicolumn{2}{|c|}{ Coda /h/ } & \multicolumn{2}{|c|}{ Coda / $/ 2 /$} \\
\hline 4.4 & & & $\mathrm{t} \int \mathrm{a}^{4} \mathrm{t} \int \mathrm{i} \mathrm{h}^{4}$ & 'tarantula' & $a^{4} t \int \tilde{1}^{4}$ & 'we pass' \\
\hline 4.43 & $a^{4} t \int \tilde{1}_{i}^{43}$ & 'to pass' & & & & \\
\hline 3.45 & & & $a^{3} t \int \tilde{1} h^{45}$ & 'to ask for' & & \\
\hline 3.4 & $\mathrm{ti}^{3} \mathrm{t}_{1}^{4}{ }^{4}$ & 'to roast' & $\mathrm{ti}^{3} \mathrm{kif}^{4}$ & 'to shove in' & $a^{3} t \int 11^{4}$ & 'we ask' \\
\hline 3.3 & $a^{3} t \int \tilde{1}_{i}^{3}$ & 'to lack' & $a^{3} t \int i f^{3}$ & 'to grow' & $a^{3} t \int_{1}^{2} 1^{3}$ & 'to bury' \\
\hline 3.2 & ta ${ }^{3}$ ?ygo: ${ }^{2}$ & 'each' & $t \int a^{3} t \int i h^{2}$ & ‘sheep' & & \\
\hline 3.1 & $\mathrm{ka}^{3} \mathrm{tin}^{1}$ & 'hip' & $\mathrm{k}^{\mathrm{w}} \mathrm{e}^{3} \mathrm{Pnif}^{1}$ & 'Wednesday' & $\mathrm{si}^{3} \mathrm{si}^{1}$ & 'sweet $(\mathrm{N})$ ' \\
\hline 3.43 & $\mathrm{ka}^{3} \mathrm{sti}^{43}$ & ‘oil' & & & & \\
\hline 3.32 & $\mathrm{ti}^{3} \mathrm{ni}^{32}$ & 'nopal cactus' & & & & \\
\hline 2.3 & $n u^{2} m \tilde{i}^{3}$ & 'tied' & $r u^{2} m i \tilde{n} h^{3}$ & 'bored' & $\mathrm{ta}^{2} \mathrm{kaP}^{3}$ & 'bent' \\
\hline 2.2 & $k u^{2} r \tilde{a}_{i}^{2}$ & ‘clear' & $\mathrm{t} \int \mathrm{i}^{2} \mathrm{koh}^{2}$ & 'jealous' & $\mathrm{ka}^{2} \mathrm{ra}^{2}$ & 'wide' \\
\hline 2.32 & $\mathrm{ma}^{2} \mathrm{res}^{32}$ & 'green' & & & & \\
\hline 1.3 & $\mathrm{ja}^{1} \mathrm{ko:}^{3}$ & 'poor' & $n u^{1} k^{w} a h^{3}$ & 'hard, strong' & & \\
\hline 1.1 & $\mathrm{ka}^{1} \mathrm{si}^{1}$ & 'white' & $\mathrm{ni}^{1} \mathrm{t} \int \mathrm{i} \mathrm{f}^{1}$ & ‘fried' & $n i^{1} \mathrm{t} \int \tilde{u} ?^{1}$ & 'near' \\
\hline
\end{tabular}

Importantly, tones $/ 4 /, / 43 /$, and $/ 45 /$ never co-occur with tones $/ 2 /, / 1 /, / 32 /$, and $/ 13 /$ in uninflected Itunyoso Triqui words. This distributional gap and the structural symmetry of the Itunyoso Triqui tonal system is captured by dividing it into distinct tonal registers; in uninflected morphemes, tones on adjacent syllables must agree in register (c.f. DiCanio 2008, 2016). This abstract classification of tones into [+UPPER] and [-UPPER] registers is not only relevant in accounting for distributional asymmetries within Itunyoso Triqui roots, but roots possessing [-UPPER] tones also systematically behave differently when inflected with stem-altering personal clitics than roots with [+UPPER] tones. The register system is given in Table $6 .{ }^{7}$

\footnotetext{
${ }^{6}$ The Triqui lexicon contains a large number of compound words as well, to which many toponyms and flora/fauna names belong.

${ }^{7}$ While not the topic of the current paper, this abstract phonological categorization of tones into features in Itunyoso Triqui is in
} 
Table 6: Tonal Register in Itunyoso Triqui (from DiCanio, 2008)

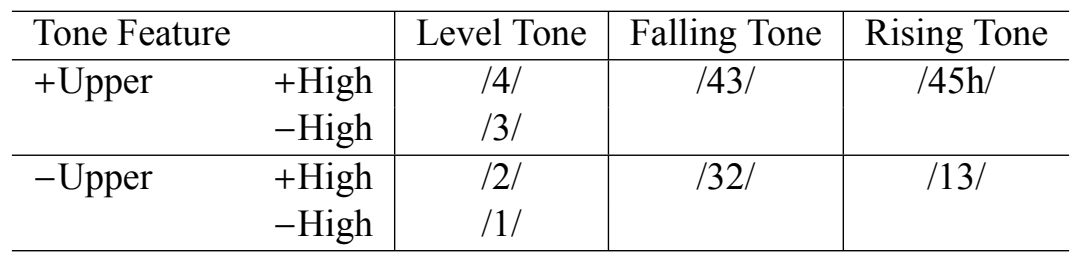

Two types of tones surface in non-final (unstressed) syllables in Itunyoso Triqui: (1) level tones which result from a process of leftward tonal association (DiCanio 2008, 2016) and (2) level tones which are underlyingly specified on non-final syllables. The latter category includes only tones $/ 2 /$ and $/ 3 / .{ }^{8}$ Incidentally, each

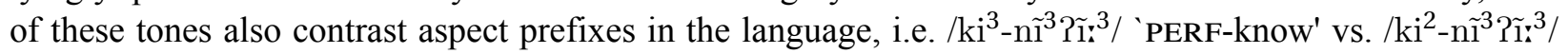
'POT-know'. DiCanio $(2016,234)$ describes the process of leftward tonal association below in (4). The autosegmental representation of this process is shown in Figure 1 for words $\left[\mathrm{t} \int \mathrm{u}^{3} \mathrm{ku}^{3}\right]$ ' animal', [t $\left.\int \mathrm{i}^{3} \mathrm{ko}^{3} \mathrm{yo:}^{3}\right]$ 'tadpole', $\left[\mathrm{ru}^{3} \mathrm{ne} \mathrm{s}^{32}\right]$ 'bean', and $\left[\mathrm{ru}^{4} n \mathrm{~s}^{43}\right]$ 'avocado.'

(4) Leftward association convention: Assign a tone or tone contour, right to left, starting on the rightmost mora (TBU) of the word and then associate the leftmost tone in the word to all preceding moras within the word.

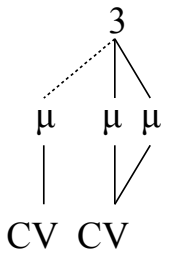

tou ku:

'animal'

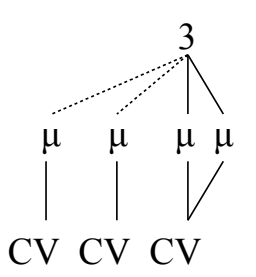

ti ko yo:

'tadpole'

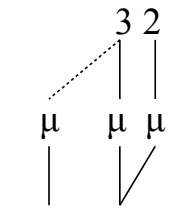

$\mathrm{CV} \mathrm{CV}$

ru ne:

'bean'

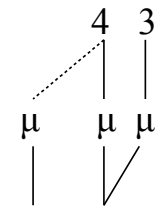

$\mathrm{CV} \mathrm{CV}$

ru ne:

'avocado'

Figure 1: Leftward tonal association in Itunyoso Triqui. Figure from DiCanio (2016).

Both phonetic evidence (lengthening) and the distribution of contour tones in Itunyoso Triqui suggests that final syllables are heavy and bimoraic, while non-final syllables are monomoraic (DiCanio 2008). One consequence of this structure is that individual tone levels are associated with single moras. DiCanio (2016, 235) also argues that each mora may be associated with only a single tone and that tonal stranding is not possible. This is captured via principles (5) and (6) below.

(5) Moraic tonal specification: A mora may be associated with only a single tone.

(6) No floating tones: Every tone must be associated with a mora.

agreement with McPherson (2017) and Yip (1993), and an additional counter-example to recent arguments that tonal features are unnecessary, i.e. Clements, Michaud \& Patin (2011); Hyman (2011); Odden (2011).

${ }^{8}$ Tone $/ 13$ / is realized across the stem on polysyllabic words, as discussed in DiCanio (2008). 
Principles (5) and (6) are necessary, DiCanio (2016) states, because their interaction produces another asymmetry observed in the data in Table 5: with the exception of tone $/ 45 /$, no contour tone may surface on a closed syllable in a polysyllabic word. ${ }^{9}$

The constraint on moraic tonal specification is satisfied for words which are polysyllabic, but violated on monosyllabic words. ${ }^{10}$ Thus, monosyllabic words like /nnã $\mathrm{h}^{32}$ / 'cigarette' are possible, but polysyllabic words (with the exception of tone $/ 45 /$ ) possessing a final contour tone and a coda are not. Reassociation of a contour tone to a preceding syllable is possible when monosyllables are prefixed though, e.g. when the possessive prefix $/ \mathrm{si}^{3}-/$ applies. ${ }^{11}$ Thus, the possessed form of 'cigarette' is [si $\left.{ }^{3}-n a ̃{ }^{2}{ }^{2}\right]$.

One particular, exceptional case of leftward movement in Itunyoso Triqui is the pattern of low tone spreading. Contour tones $/ 43,32,13$ / are each associated to the right edge of the stem in polysyllabic words. Tones preceding the stem-final syllable are usually the result of principle (4) above (leftward tonal association). On trisyllabic roots, this produces patterns [4.4.43, 3.3.32, 1.1.3]. Patterns without rightmost tonal association are unattested in the language $*[3.4 .4,4.3 .3,3.3 .2,3.2 .2,1.3 .3]$. However, the same pattern is not observed with tone /31/; on polysyllabic words, [3.1] and [3.1.1] are observed but *[3.31, 3.3.1, 3.3.31] are not observed. This pattern suggests that tone /1/ spreads leftward. DiCanio $(2016,239)$ describes this rule as in (7) below with an autosegmental derivation given in Figure 2 for the word $\left[\mathrm{a}^{3} \mathrm{t} \int \mathrm{i}^{1} \mathrm{Pi}^{1}{ }^{1}\right.$ ' to begin.'

(7) Low tone spreading: A low /1/ tone associated to the rightmost mora must spread leftward iteratively to the leftmost edge of the phonological word.

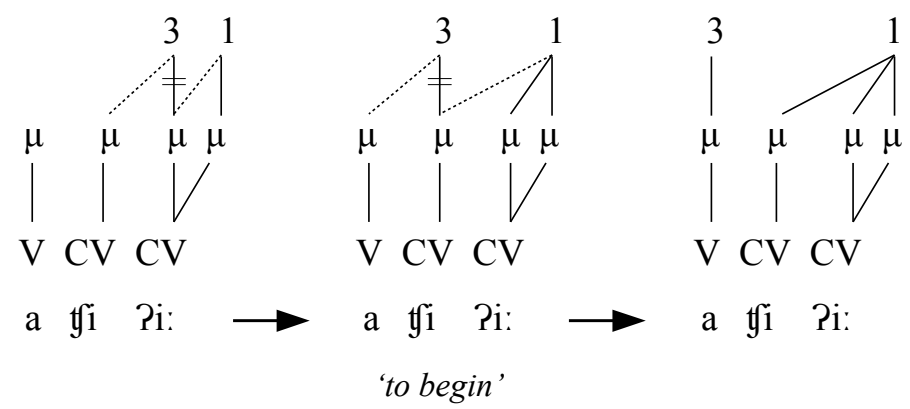

Figure 2: Leftward tonal association and iterative low tone spreading. Figure from DiCanio (2016)

When words with tone $/ 31$ / are prefixed in Itunyoso Triqui, low tone spreading obligatorily takes place,

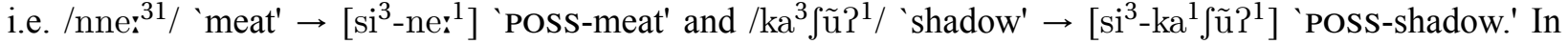
both these examples, tone $/ 3 /$ remains on the phonological word. Low tone spreading will never delete a preceding tone, in accordance with the more highly ranked MAX(Tone) constraint. The result of this process is what appears, superficially, to be two types of alignment patterns with contour tones in Itunyoso Triqui. On the one hand, leftward tonal association involves tones aligned at the right edge of the root and redundant tones to the left. On the other hand, low tone spreading creates what appears to be tonal alignment on the leftmost syllable redundant tones to the right. Note that this process is general and can be triggered by the 2S clitic $/=\mathrm{re}^{1} /$ as well (c.f. DiCanio 2016), where cliticization causes stem-tonal changes, i.e. $/ \mathrm{ko}^{4} \mathrm{Po}^{43} /$

\footnotetext{
${ }^{9}$ While not stated as such in DiCanio (2016), principles (5) and (6) are essentially equivalent to the optimality theoretic constraints *CONTOUR and *FLOAT, respectively (Yip 2002).

${ }^{10}$ This pattern suggests that another tonal constraint is active in Itunyoso Triqui: $M A X-I O($ Tone); tones may not be deleted.

${ }^{11}$ In autosegmental terms, the initial tone $/ 3 /$ of the stem is absorbed by the prefix; tonal absorption.
} 
'PERF.drink' $\rightarrow\left[\mathrm{ko}^{4} \mathrm{Po:}^{1}=\mathrm{re}^{1}\right]$ 'you drank.' The low tone of the clitic spreads one syllable to the left and replaces the preceding syllable's tones.

\subsection{Itunyoso Triqui morphology and stem allomorphy}

An important consideration for clitic morphophonology in Itunyoso Triqui is the stem type to which the clitic applies. To provide some background on the morphological system, affixes are prefixal and only personal clitics may occur at the right edge of the word. ${ }^{12}$ Words of any part of speech may contain a personal enclitic, but alienable nouns may be preceded by a single possessive prefix $/ \mathrm{si}^{3}-/$; and verbs may be preceded by causative $/ \mathrm{t}(\mathrm{V})-/$ or iterative $/ \mathrm{n}(\mathrm{V})-/$ prefixes and/or by an aspectual prefix $/ \mathrm{k}(\mathrm{V})-/$. Owing to the nature of clitics, they can freely attach to words of most parts of speech. General, verbal, and nominal morphological templates are shown below in items (8) - (10).

(8) General template: STEM=(NUM)+(CLITIC)

(9) Nominal template: (POSS)--NOUN=(NUM)+(CLITIC)

(10) Verbal template: $($ CAUS/ITER $)--($ ASP $)-$-VERB $=($ SUBJ.CLITIC $)=($ OBJ.CLITIC $)$

The personal clitics which condition morpheme-specific tonal changes on the stem-final syllable include the $1 \mathrm{~s}$, the $2 \mathrm{~s}$, the $3 \mathrm{TS}$ (topical $3^{\text {rd }}$ person), and the 1.DU. We may call this class tonally-integrating clitics since the tonal exponents of the clitic are fully or partially realized on the stem itself. None of the other clitics do condition tonal changes on stems. ${ }^{13}$

There are three types of stem formation that we must distinguish prior to discussing clitic-specific morphophonology. ${ }^{14}$ The first type is stem formation applying prior to the application of cliticization. This stem formation process occurs with a subset of nouns and with potential aspect marking on verbs. For the nouns, the possessed stem carries a distinct tonal shape from the unpossessed root. These possessed stems have tones $/ 1 /$ or $/ 2 /$ and are irregular (lexically specified). Of the 507 paradigms examined for the current paper, only 33 stems $(7.1 \%)$ show this irregular pattern.

Observe the paradigms given in Table 7. Paradigms (a) and (c) show bare nouns with tonal melody /3.4/ and paradigms (b) and (d) show bare nouns with tone /4/. However, in both (a) and (b), the tone on the possessed stem is $/ 1 /$. This irregular stem tone is used for all possessed forms of these nouns, including the 3 s.MASC clitic $/=\mathrm{sih}^{3} /$ which does not condition any tonal changes on Itunyoso Triqui stems. These are lexicalized low-toned stems. The tonal alternations involved in stem formation are distinct from those associated with particular clitics since they apply uniformly across the paradigm irrespective of the clitic. ${ }^{15}$ The nominal stem tonal allomorphy is similar to tonal changes that occur with potential aspect on verbs (shown in Table 9 below). The tone on the verb root is also replaced by tones $/ 2 /$ or $/ 1 /$, and like the nominal stem allomorphy, tonal replacement with the potential aspect is independent from clitic-conditioned tonal rules.

\footnotetext{
${ }^{12}$ A key for all abbreviations of grammatical/morphological categories is given in an appendix at the end of the paper.

${ }^{13}$ This split between clitics which condition tonal changes on the stem and those which do not is similar to the split between tonally-integrating and non-tonally integrating affixes in Hausa (Newman 2000), though in the Triqui context this distinction applies within the set of personal clitics.

${ }^{14}$ For the purposes of this paper, we distinguish between 'roots' as the phonological shapes of a morphemes that are uninflected and 'stems' as the phonological shapes of roots when an affix applies.

151 .DU cliticization involves a vowel alternation where $/ \mathrm{a} / \rightarrow / \mathrm{o} /$ and $/ \tilde{\mathrm{a}} / \rightarrow / \tilde{\mathrm{u}} / ;$ in featural terms $[+$ low, + back $] \rightarrow[-$ low $]$. Throughout the paper, we refer to this clitic as " 1 .DU", though it is often used as a generic 1 st person plural, i.e. distinct from the $1^{\text {st }}$ person plural inclusive clitic $/=\mathrm{ne}^{4} /$ and $1^{\text {st }}$ person plural exclusive clitic $/=\tilde{u} \mathrm{~h}^{4} \%$.
} 
Table 7: Stem-tonal allomorphy

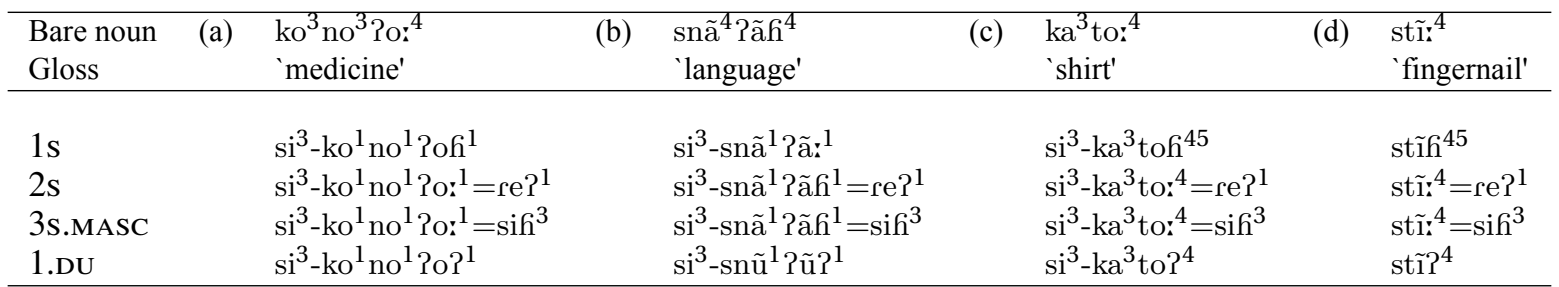

The second type of Triqui stem formation is conditioned by a specific class of clitics and is also lexically specified. These stems have a raised tone when preceding the 1s, 2s, and 1.DU clitics (see DiCanio 2016). These three clitics are a subset of the tonally-integrating clitics described above (those which condition tonal changes on the stem) and, as a class, involve those entities that are within the immediate discourse context. We call these IDCM (immediate discourse context modified) stems. Thus, there is a difference in Itunyoso Triqui between roots which take an alternate tonal stem irrespective of the particular clitic and those that only take an alternate tonal stem for the $1 \mathrm{~s}, 2 \mathrm{~s}$, and 1 .DU clitics. For instance, the word $/ \mathrm{t} \mathrm{fi}^{3} \mathrm{ri}^{3} /$ 'intestines' $\rightarrow$ [t $\left.\int \mathrm{i}^{4} \mathrm{rih}^{4}\right]$ 'my intestines'; [t $\left.\int \mathrm{i}^{4} \mathrm{rih}^{1}=\mathrm{re}^{1}\right]$ 'your intestines'; [t $\left.\mathrm{i}^{4} \mathrm{rih}^{4}\right]$ 'our intestines'; [t $\left.\mathrm{i}^{3} \mathrm{rih}^{3}=\mathrm{sih}^{3}\right]$ 'his intestines'. For only those clitics in the IDCM class do we observe a stem tone [4] instead of [3].

The third type of stem formation in Itunyoso Triqui is the simplest - the stem tone is equivalent to the root tone prior to the application of clitic-specific morphophonology. In sum, a word in Itunyoso Triqui either takes no stem-level tonal modifications; stem-level tonal modifications with the $1 \mathrm{~s}, 2 \mathrm{~s}$, and 1.DU clitics; or stem-level tonal modifications irrespective of the clitic. These stem formation processes are independent from morpheme-specific tonal phonology and are summarized below:

(11) Unmodified stem: No stem-level tonal changes occur on a root.

(12) Immediate discourse context modified (IDCM) stem: a stem-level tonal allomorph co-occurs with the $1 \mathrm{~s}, 2 \mathrm{~s}$, and 1.DU clitics. The root's tone changes to a higher tone.

(13) Modified stem: A stem-level tonal allomorph co-occurs irrespective of the clitic (as in Table 7). The root's tone changes to $/ 2 /$ or $/ 1 /$.

One way to capture these distinctions in Itunyoso Triqui stems is with distinct morphophonological strata, or levels, schematized below in Table $8 .{ }^{16}$ Stratum 1 involves tonal changes with clitic-modified stems. Subsequent tonal processes applying at stratum 2 are insensitive to the tonal identity of the bare root in Itunyoso Triqui.

Table 8: Strata in Itunyoso Triqui

\begin{tabular}{lllc}
\hline & Input & Output & Process applying \\
\hline Stratum 1: & Root & Stem 1 & Potential verb aspect, suppletive stem-allomorphy \\
Stratum 2: & Stem 1 & Stem 2 & Enclitic pronouns \\
\hline
\end{tabular}

This separation of Triqui word formation into distinct strata is not only motivated by tonal changes with modified stems, but also by segmental changes that occur on certain lexical items. For instance, a small class of roots, like $/ \mathrm{Be}^{3} /$ ' house', take suppletive stem allomorphs when possessed, e.g. $/ \mathrm{tu}^{3} \mathrm{k}^{\mathrm{w}} \mathrm{a}^{4} /$ 'POss.house.' These segmentally-distinct stems would be formed in the initial stratum. Thus, the suppletive stem allomorph

\footnotetext{
${ }^{16} \mathrm{~A}$ formal analysis of these levels/domains of word formation is beyond the scope of the current paper, though stratal approaches to phonological structure would seem to be most relevant, c.f. Kiparsky (2000); Bermúdez-Otero (2017); Inkelas \& Zoll (2007).
} 
class includes these obvious, segmentally-distinct allomorphs, modified stems (changing to tone $/ 2 /$ or $/ 1 /$ ), and IDCM stems. Table 9 shows derivations of tonal changes with verbal aspect (see DiCanio 2020) in the two paradigms at the top and derivations of nouns with suppletive stem allomorphy in the two paradigms at the bottom.

The stem types reflect only the shape of the stem to which the more regular clitic-conditioned tonal changes apply. Consider the verbal derivation shown in Table 9. The perfective aspect does not condition stem-level tonal changes in stratum 1 . The 1 s clitic conditions tonal changes on this stem at stratum 2. However, the potential aspect for this same verb (on the right) conditions stem-level tonal changes in stratum 1 (to tone $/ 2 /$ ). In stratum 2, the $1 \mathrm{~s}$ clitic conditions further tonal changes on this stem. These initial levels of analysis are a necessary precursor to understanding the tonal processes conditioned by the 1s clitic which accompany a morphophonological reversal. Moreover, the tonal change associated with the $1 \mathrm{~s}$ clitic changes based on verbal aspect. In the perfective (and habitual) aspect, the tone of the final syllable changes from $/ 5$ $\rightarrow 43 /$. In the potential aspect, the tone of the verbal stem changes from $/ 2 \rightarrow 1 /{ }^{17}$

Table 9: Examples of strata in Itunyoso Triqui

\begin{tabular}{|c|c|c|c|c|c|}
\hline & & Word & Gloss & Word & Gloss \\
\hline \multirow[t]{2}{*}{ Stratum 1} & Input & $\mathrm{a}^{3} \operatorname{chi\tilde {1}}{ }^{5}$ & ask.for & $\mathrm{a}^{3} \operatorname{chĩ}^{5}$ & ask.for \\
\hline & Output & $\mathrm{k}-\mathrm{a}^{3} \operatorname{chinh}^{5}$ & PERF-ask.for & $\mathrm{k}-\mathrm{a}^{2} \operatorname{chĩh^{2}}$ & POT-ask.for \\
\hline \multirow[t]{2}{*}{ Stratum 2} & Input & $\mathrm{ka}^{3} \operatorname{chĩh}^{5}$ & PERF.ask.for & $\mathrm{ka}^{2} \operatorname{chĩh}{ }^{2}$ & POT.ask.for \\
\hline & Output & $\mathrm{ka}^{3} \operatorname{chĩi}{ }^{43}$ & PERF.ask.for.1s & $\operatorname{ka}^{1} \operatorname{ch} \tilde{l}_{i}^{1}$ & POT.ask.for.1s \\
\hline \multirow[t]{2}{*}{ Stratum 1} & Input & $\beta e ?^{3}$ & house & $\mathrm{ko}^{3} \mathrm{no}^{3} \mathrm{Po}^{4}$ & medicine \\
\hline & Output & $t u^{3} k^{w} a^{4}$ & POss.house & $\mathrm{si}^{3}-\mathrm{ko}^{1} \mathrm{no}^{1} \mathrm{Po}^{1}$ & POSS-medicine \\
\hline \multirow[t]{2}{*}{ Stratum 2} & Input & $t u^{3} k^{w} a^{4}$ & POss.house & $\mathrm{si}^{3} \mathrm{ko}^{1} \mathrm{no}^{1} \mathrm{Po}^{1}$ & POss.medicine \\
\hline & Output & $\mathrm{tu}^{3} \mathrm{k}^{\mathrm{w}} \mathrm{a} \mathrm{h}^{45}$ & POss.house.1s & $\mathrm{si}^{3} \mathrm{ko}^{1} \mathrm{no}^{1}$ Poh $^{1}$ & POSS.medicine.1s \\
\hline
\end{tabular}

\subsection{Glottal toggling in the $1 \mathrm{~s}$ clitic}

The 1s clitic is marked via two morphological exponents in Itunyoso Triqui: tonal changes and glottal toggling. In simple terms, if a stem-final syllable does not have a coda $/ \mathrm{h} /, / \mathrm{h} /$ is appended to the right edge of the stem. If a stem-final syllable has a coda $/ \mathrm{h} /$, it is deleted. As per Itunyoso Triqui phonology, stem-final syllables which do not have codas have predictable long vowels. While the segmental exponents of the $1 \mathrm{~s}$ clitic are regular and easily predictable, the tonal exponents are more complex. We describe the segmental processes here and the tonal processes in the next section.

Examples of the segmental toggling process are given in Table 10. ${ }^{18}$ All words undergo glottal toggling, so it is a productive process. The roots given in (a)-(e) each have a final open syllable and / $/$ / is inserted with the $1 \mathrm{~s}$ clitic. The roots given in (f)-(j) each possess a coda $/ \mathrm{h} /$ which is deleted in the $1 \mathrm{~s}$ form.

\footnotetext{
${ }^{17}$ Note that the deletion of the coda is consistent across aspects, an important consideration we explore below.

${ }^{18}$ Alienably-possessed nouns which are $/ \mathrm{j} /$-initial undergo a consonant mutation of $/ \mathrm{j} / \rightarrow / \mathrm{t} /$ as an allomorph of the possessive prefix, see DiCanio (2016).
} 
Table 10: Glottal toggling of 1st person singular in Itunyoso Triqui

\begin{tabular}{|c|c|c|c|}
\hline Bare root & Gloss & Inflected stem & Gloss \\
\hline (a) $a^{4} n \tilde{r}^{43}$ & 'to stop' & $a^{4} n \tilde{1} h^{4}$ & 'I stop' \\
\hline (b) $\mathrm{so}^{3} \mathrm{Po:}^{3}$ & 'be deaf' & so $^{3}$ Poh $^{45}$ & 'I am deaf' \\
\hline (c) nne: $:^{3}$ & 'plough' & $\mathrm{si}^{3}-\mathrm{neh}^{45}$ & 'my plough' \\
\hline (d) $k u^{3} r u i^{32}$ & 'granary' & $\mathrm{si}^{3}-\mathrm{ku}^{1} \mathrm{ruh}^{1}$ & 'my granary' \\
\hline (e) jã : & 'salt' & tã $h^{3}$ & 'my salt' \\
\hline (f) $a^{4} n \tilde{n} h^{4}$ & 'to get dirty' & $a^{4} n \tilde{1}_{:}^{43}$ & 'I am getting dirty' \\
\hline (g) $\mathrm{jo}^{3}$ Poh $^{45}$ & 'land' & to ${ }^{3}$ o: $^{43}$ & 'my land' \\
\hline (h) nnef ${ }^{3}$ & 'dream' & $\mathrm{si}^{3}-n \mathrm{e}^{32}$ & 'my dream' \\
\hline (i) $\mathrm{ni}^{3} \mathrm{naf}^{3}$ & 'to be tired' & $n i^{3} n a i^{32}$ & 'I am tired' \\
\hline (j) jã $h^{3}$ & 'paper' & tã: $:^{43}$ & 'my paper' \\
\hline
\end{tabular}

If a stem-final syllable has a coda $/ \mathrm{R} /$, this coda is usually replaced by $/ \mathrm{h} /$. For certain irregular roots in Itunyoso Triqui, a coda $/ 2 /$ is not replaced by $/ \mathrm{h} /$, but these roots undergo vowel reduplication instead. In this pattern, a / $\mathrm{Vh} /$ suffix is applied where the vowel is an identical copy of the vowel preceding the glottal stop, i.e. ...(CV)CV $\mathrm{CV}_{a} \mathrm{P}=\mathrm{V}_{a}$ h. Regular and irregular roots are shown in Table 11. Of the 507 paradigms examined in this paper, 105 stems have a final coda $/ 2 /$. Of these, only 22 stems take the reduplicative $/-\mathrm{Vh} /$ allomorph shown in (b). The remaining 83 stems take the regular pattern shown in (a). However, there is variation where forms which take the reduplicative $1 \mathrm{~s}$ allomorph may be produced with the regular allomorph, e.g. $\left[\mathrm{na}^{3} \mathrm{no}^{3} \mathrm{Poh}^{45}\right] \sim\left[\mathrm{na}^{3} \mathrm{noh}^{45}\right]$ 'I look for'. This suggests that the irregular forms may be undergoing regularization. This variation may be motivated in part by a general process whereby intervocalic glottal stops are lenited (c.f. DiCanio 2012a).

Table 11: Regular (a) and irregular (b) 1s marking on stems with coda /2/. This table is modified from DiCanio (2016).

\begin{tabular}{|c|c|c|c|c|}
\hline & Bare root & Gloss & 1s stem & Gloss \\
\hline \multirow[t]{6}{*}{ (a) } & $n a^{3}$ t $\int \tilde{a} ?^{3}$ & 'to turn' & $n a^{3} t \int a ̃ h^{45}$ & 'I turn' \\
\hline & $\mathrm{to}^{3} \mathrm{ko}^{1}$ & 'to hang (tr.)' & to $^{4}$ koh $^{4}$ & 'I hang' \\
\hline & ${ }^{3}$ na? $^{3}$ & 'to come' & ${ }^{2}$ nafi $^{45}$ & 'I am coming' \\
\hline & $\mathrm{ka}^{3} \operatorname{sip}^{3}$ & `honey' & $\mathrm{si}^{3}-\mathrm{ka}^{3} \sin ^{45}$ & 'my honey' \\
\hline & $\operatorname{sta}^{3} \operatorname{ygal}^{3}$ & 'nape' & sta $^{3} \mathrm{ygah}^{45}$ & 'my nape' \\
\hline & kkã $\Upsilon^{3}$ & 'corn dough' & $\mathrm{si}^{4}-\mathrm{kã} \mathrm{h}^{4}$ & 'my corn dough' \\
\hline \multirow[t]{6}{*}{ (b) } & $k \tilde{\imath} ?^{3}$ & 'to stink' & kĩ $\tilde{1}^{3} \tilde{i} \mathrm{~h}^{45}$ & 'I stink' \\
\hline & na ${ }^{3}$ no ${ }^{3}$ & 'to look for' & na $^{3}$ no $^{3}$ poh $^{45}$ & 'I look for' \\
\hline & $n a^{2}$ rã ${ }^{3}$ & 'to pick up (mass N.)' & $n a^{2}$ rã $\tilde{a}^{3} \tilde{a}^{45}$ & 'I pick up' \\
\hline & $\mathrm{ka}^{3} \mathrm{ya}^{3}$ & 'bottle, metal' & $\mathrm{si}^{3}-\mathrm{ka}^{3} \mathrm{ya}^{3} \mathrm{Pah}^{45}$ & 'my bottle, metal' \\
\hline & $k a^{3} t \int \tilde{u} ?^{1}$ & 'shadow' & $\mathrm{si}^{3}-\mathrm{ka}^{1} \mathrm{t} \int \tilde{\mathrm{u}}^{1} P \tilde{u} \mathrm{~h}^{1}$ & 'my shadow' \\
\hline & jã $1^{3}$ & 'tooth' & jã $\tilde{a}^{3} \tilde{a}^{45}$ & 'my tooth' \\
\hline
\end{tabular}

\subsubsection{Types of tonal changes with 1s cliticization}

The tonal alternations associated with the $1 \mathrm{~s}$ clitic are determined by (a) the tonal identity and tonal register of the stem (upper or lower); (b) the directionality of the segmental toggle and (c) the stem type (as shown above). For stems with certain tones $(/ 1,2,4 /)$, the patterns are generally predictable. For the remainder (tones 
$/ 3,32,31,13,45 /)$, there are statistical tendencies but one cannot deterministically predict the $1 \mathrm{~s}$ stem tone on the basis of the bare root tone. However, one can group the set of tonal alternations into five major categories, some of which correspond to the stem types shown in $\$ 2.3$. General principles of tonal well-formedness also govern the possible tonal shapes that the $1 \mathrm{~s}$ stem may possess. Among these five groups, there are three major and two minor patterns. These account for $94.9 \%$ of the tonal changes observed with the $1 \mathrm{~s}$ clitic and are provided in Table 12 . The remaining $5.1 \%$ of paradigms (26 paradigms) are suppletive.

Table 12: $1 \mathrm{~s}$ tonal patterns

\begin{tabular}{l|l}
\hline Tonal pattern with $1 \mathrm{~s}$ clitic & Percentage of paradigms \\
\hline Tone $/ 4 /$ or $/ 43 /$ stem & $145 / 507=28.6 \%$ \\
Final syllable raising to $/ 45 \mathrm{~h} /$ & $126 / 507=24.9 \%$ \\
Insertion/deletion of $/ 3 /$ or $/ 2 /$ with toggling & $136 / 507=26.8 \%$ \\
No tone change & $51 / 507=10.1 \%$ \\
Lowering to $/ 1 /$ & $23 / 507=4.5 \%$ \\
\hline
\end{tabular}

\section{Minor tonal patterns}

The two minor patterns are (1) the absence of a tone change and (2) lowering to tone $/ 1 /$. The words for which no tonal changes occur consist mostly of roots with tone $/ 1 /$ or $/ 31 / 19$, or derived stems with tone $/ 1$ / (modifed stems). These comprise 46/51 paradigms with no tonal change with the 1 s clitic $(90.1 \%)$. This lack of an alternation may be rarer in Itunyoso Triqui, given that tone /1/ is found mostly on adjectives; it is rare on nouns (just 12 nouns have this tone), and never surfaces on verbs. The lowering to tone $/ 1 /$ pattern is found specifically on roots with tone $/ 2$ / or roots with stem $/ 2$ / allomorphs. While this latter pattern appears rare, according to Table 12, it is in fact the regular pattern for many verbs inflected for the potential aspect whose stems change tone to $/ 2 /{ }^{20}$ Examples of each of these patterns are given in Table 13 .

Table 13: Non-tone-changing stems and tone lowering stems with 1s cliticization

\begin{tabular}{|c|c|c|c|c|c|}
\hline \multicolumn{3}{|c|}{ Non-changing } & \multicolumn{3}{|c|}{ Tone lowering } \\
\hline Gloss & Bare stem & 1s stem & Gloss & Bare stem & 1s stem \\
\hline 'illness' & $s i^{3}-t \int i^{1} P i_{i}^{1}$ & $s i^{3}-t \int i^{1} P i h^{1}$ & 'food' & $\mathrm{si}^{3}-\mathrm{ni}^{2} \mathrm{yai^{2 }}$ & $\mathrm{si}^{3}-\mathrm{ni}^{1} \mathrm{yah}^{1}$ \\
\hline 'tamal' & $\mathrm{si}^{3}-\mathrm{nu}^{1} \mathrm{ta}^{1}$ & $\mathrm{si}^{3}-\mathrm{nu}^{1} \mathrm{tah}^{1}$ & 'thing' & $\mathrm{si}^{3}-\mathrm{ra}^{2} \mathrm{su}_{i}^{2}$ & $\mathrm{si}^{3}-\mathrm{ra}^{1} \mathrm{su}^{1} \mathrm{~h}^{1}$ \\
\hline 'candy' & $\mathrm{si}^{3}-\mathrm{si}^{1} \mathrm{siP}^{1}$ & $\mathrm{si}^{3}-\mathrm{si}^{1} \mathrm{sih}^{1}$ & 'liver' & $\mathrm{si}^{3}-\mathrm{t} \int \mathrm{a}^{2} \mathrm{yah^{2 }}$ & $s i^{3}-t \int a^{1} y a:{ }^{1}$ \\
\hline $\sin ^{\prime}$ & $\mathrm{si}^{3}-\mathrm{ke}^{1}$ & $\mathrm{si}^{3}-\mathrm{keh}^{1}$ & 'cotton' & $\mathrm{si}^{3}-\mathrm{ka}^{2} \mathrm{t} \int \mathrm{i} \mathrm{h}^{2}$ & $\mathrm{si}^{3}-\mathrm{ka}^{1} \mathrm{t} \int \mathrm{ir}^{1}$ \\
\hline 'shame' & $\mathrm{si}^{3}-\mathrm{na}^{1}{ }^{1} \mathrm{ah}{ }^{1}$ & $s i^{3}-n a^{1} P a:^{1}$ & 'short' & $\operatorname{tt} \int \mathrm{e} ?^{2}$ & $\operatorname{tt} \int \mathrm{eh}^{1}$ \\
\hline 'naked' & kã $h^{1}$ & $k \tilde{a}_{:}^{1}$ & 'POT.go' & $k \tilde{a}^{2} P a ̃ h^{2}$ & kã ${ }^{1} P \tilde{a}_{i}^{1}$ \\
\hline 'to begin' & $a^{3} t \int i^{1} P i_{i}^{1}$ & $a^{3} t \int i^{1} P i h^{1}$ & 'POT-scratch' & $k-u^{2} t u i^{2}$ & $\mathrm{ku}^{1} \mathrm{tuh}^{1}$ \\
\hline 'to hope' & $a^{3}$ no $^{1}$ Poh $^{1}$ & $a^{3}$ no ${ }^{1}$ o: $^{1}$ & 'POT.eat' & $t \int a i^{2}$ & $\mathrm{t} \int a h^{1}$ \\
\hline
\end{tabular}

The forms given in Table 13 consist of bare stems and $1 \mathrm{~s}$ cliticized stems. The bare stems here reflect the output of low tonal spreading for tone $/ 31$ / for the 'non-changing' category and the irregular tone $/ 2 /$ stems for the 'tone lowering' category, e.g. the bare noun for 'food' is $\left[\mathrm{ni}^{3} \mathrm{yai}^{32}\right]$, but the stem tonal allomorph used with possession is always tone $/ 2 /$. Note that the $/ \mathrm{h} /$-toggling process applies as the sole exponent for the 1s clitic for the non-tone-changing category. For the tone-lowering category, tone is lowered $(/ 2 / \rightarrow / 1 /)$ as

\footnotetext{
${ }^{19}$ Recall that tone $/ 31 /$ is left-aligned with a stem-final tone $/ 1 /$ (c.f. Figure 2 ).

${ }^{20}$ These patterns are excluded from the current counts since their inclusion would involve counting the same verb root (uninflected and inflected stems) twice.
} 
an additional exponent with /h/-toggling. Here, tone lowering to /1/ occurs regardless of the direction of the toggling (insertion or deletion).

\section{Major tonal patterns}

For IDCM stems, there are two types of tonal alternations in Itunyoso Triqui: tonal replacement on the entire stem and final syllable stem tone replacement. In the first pattern, if the final syllable of the root does not have a stem-final coda $/ \mathrm{h} /$, the tone of the derived 1 s stem when $/ \mathrm{h} /$ is inserted is $/ 4 /$. If the final syllable of the root does have a coda $/ \mathrm{h} /$, the tone of the derived $1 \mathrm{~s}$ stem when $/ \mathrm{h} /$ is deleted is $/ 43 /$. Note that the set of tonal alternations which apply to these derived stems are identical to those which apply to roots possessing underlying tone $/ 4 /$ or $/ 43 /$. That is, roots which take high tone stem allomorphs are identical on the surface to underlying high toned roots. For instance, the $1 \mathrm{~s}$ form for both $/ \mathrm{t} \int \mathrm{a} \mathrm{a}^{43} /{ }^{4}$ to eat' and $/ \mathrm{t} \mathrm{a} \mathrm{a}^{31} /$ 'head' is $\left[\mathrm{t} \int \mathrm{ah}^{4}\right]$; and the $1 \mathrm{~s}$ form for both $/ \mathrm{Bah}^{4} /$ 'to grind' and $/ \mathrm{Bah}^{3} /$ 'to go' is $\left[\beta \mathrm{a}_{\mathrm{i}}^{43}\right]$. The latter member of each of these pairs is a stem with a derived high tone allomorph.

Table 14: Tone /4/ and /43/ stem allomorphy with 1 s clitic

\begin{tabular}{|c|c|c|c|c|c|}
\hline \multicolumn{3}{|c|}{ Derived /4/ and /43/ stems } & \multicolumn{3}{|c|}{ Underlying /4/ and /43/ stems } \\
\hline Gloss & Bare root & 1s stem & Gloss & Bare root & 1s stem \\
\hline 'head' & t $\int a:^{31}$ & $\mathrm{t} \int \mathrm{a} h^{4}$ & 'to eat' & tfa: ${ }^{43}$ & $\mathrm{t} \int a h^{4}$ \\
\hline 'knee' & ta ${ }^{3}$ mã: $:^{1}$ & $\mathrm{ta}^{4} \mathrm{Pmã} \mathrm{h}^{4}$ & ‘skirt' & $\mathrm{ste}^{4} \mathrm{ku}:^{43}$ & $\mathrm{si}^{3}-$ ste $^{4} \mathrm{kuh}^{4}$ \\
\hline 'tail' & $\mathrm{tu}^{3}$ ne? $\mathrm{P}^{3}$ & $\mathrm{tu}^{4} \mathrm{neh}^{4}$ & 'to give' & $\mathrm{ri}^{4} \mathrm{ki}^{43}$ & $\mathrm{ri}^{4} \mathrm{kih}^{4}$ \\
\hline 'to sow' & $u^{3} n \tilde{u}_{:}^{32}$ & $\mathrm{u}^{4} \mathrm{nu} \mathrm{h}^{4}$ & 'to light (fire)' & $a^{4} n \tilde{u}^{43}$ & $a^{4} n \tilde{u} h^{4}$ \\
\hline 'to sweep' & $\mathrm{na}^{3} \mathrm{kaP}^{3}$ & $\mathrm{na}^{4} \mathrm{kah}^{4}$ & 'garlic' & $\mathrm{ya}^{4} \mathrm{ku}^{43}$ & $\mathrm{si}^{3}-\mathrm{ya}^{4} \mathrm{kuf}^{4}$ \\
\hline $\operatorname{pot}^{\prime}$ & $t \int u h^{3}$ & $s i^{3}-t \int u i^{43}$ & to push' & $\mathrm{t} \int \tilde{a} \mathrm{~h}^{4}$ & $\mathrm{t} \int \tilde{a}_{:}^{43}$ \\
\hline thorn' & ttã $h^{3}$ & $s i^{4}-t a:_{:}^{43}$ & 'to buy' & rã $h^{4}$ & rã: \\
\hline 'to go' & $\beta a h^{3}$ & $\beta a:^{43}$ & 'to grind' & $\beta a h^{4}$ & $\beta a^{43}$ \\
\hline to grow' & $a^{3} t \int i h^{3}$ & $a^{4} t \int i_{:}^{43}$ & 'to sneeze' & $a^{4} t \int \tilde{1} h^{4}$ & $a^{4} t \int \tilde{1}_{i}^{43}$ \\
\hline
\end{tabular}

Though replacement of the stem tone is not phonologically conditioned, the choice of tone is predictable on phonological grounds. That is, stems with a final coda carry tone $/ 4 /$, but stems with no coda carry tone /43/. This agrees with the general pattern of tonal well-formedness which disprefers contours on syllables with codas. Examples of this stem allomorphy are provided in Table 14.

The second pattern for IDCM stems involves raising of the final tone on the stem to a higher tone. DiCanio (2016) provides an account of these types of stems in Itunyoso Triqui, which he calls tone-raising stems. The $1 \mathrm{~s}$ clitic involves tonal raising to $/ 45 \mathrm{~h} /$. Recall that the high rising tone $/ 45 /$ only surfaces with a coda $/ \mathrm{h} /$. Since tonal raising only occurs with $/ \mathrm{h} /$-insertion, no roots with a coda $/ \mathrm{h} /$ undergo the process. The process affects the stem-final syllable of certain bare roots with tone $/ 3 /$, tone $/ 4 /$, and most with melody 13.4/. Examples of this process are provided in Table 15.

Table 15: Tone $/ 45 \mathrm{~h} /$ raising with $1 \mathrm{~s}$ clitic

\begin{tabular}{|c|c|c|c|c|c|}
\hline Gloss & Bare root & 1s stem & Gloss & Bare root & 1s stem \\
\hline 'hand' & $\mathrm{ra}^{3} \mathrm{~Pa} \mathrm{~s}^{3}$ & $\mathrm{ra}^{3} \mathrm{Pah}^{45}$ & 'to faint' & $n i^{3} t \int e:^{3}$ & $\mathrm{ni}^{3} \mathrm{t} \int \mathrm{eh}^{45}$ \\
\hline 'stomach' & $\mathrm{ri}^{3} \mathrm{ki}^{3}$ & $\mathrm{ri}^{3} \mathrm{kif}^{45}$ & 'to listen' & $u^{3} n \tilde{u}_{:}^{3}$ & $u^{3} n \tilde{u} h^{45}$ \\
\hline 'uncle' & $\mathrm{ta}^{3} \mathrm{Pn} \tilde{\mathrm{u}} \mathrm{P}^{3}$ & $\mathrm{ta}^{3} \mathrm{Pn} \tilde{u} \mathrm{~h}^{45}$ & 'to hit' & $o ?^{3}$ & $\mathrm{oh}^{45}$ \\
\hline 'ice' & $\mathrm{ju} \mathrm{u}^{3} \mathrm{p} \beta \mathrm{e} \mathrm{P}^{3}$ & $\mathrm{tu}^{3} \mathrm{p} \beta \mathrm{eh}{ }^{45}$ & 'to be afraid' & $\mathrm{t} \int \mathrm{u}^{3} \mathrm{P} \beta \mathrm{i} \mathrm{P}^{3}$ & $\mathrm{t} \int \mathrm{u}^{3} P \beta \mathrm{i} \mathrm{h}^{45}$ \\
\hline 'neck' & $\mathrm{t} \int \mathrm{a}:^{4}$ & $\mathrm{t} \int a h^{45}$ & 'to sew' & $n a^{3} n u^{3} \beta a:^{4}$ & $n a^{3} n u^{3} \beta a h^{45}$ \\
\hline 'shirt' & $\mathrm{ka}^{3}$ to: $^{4}$ & $\mathrm{si}^{3}-\mathrm{ka}^{3} \mathrm{toh}^{45}$ & 'to roast' & $\mathrm{ti}^{3} \mathrm{ti}^{4}$ & $\operatorname{ti}^{3} \operatorname{tĩh}^{45}$ \\
\hline
\end{tabular}


The final major class of patterns of tonal alternations with the 1 s clitic involve tonal insertion and deletion. These occur on unmodified stems carrying tones $/ 45,43,32,4,3 /$; no lower register tones undergo this alternation. Table 14 above shows examples of words with underlying tone /4/ and /43/, both of which fall into this category. Additional examples with these and other tones are given in Table 16.

Table 16: Tonal insertion and deletion with the 1s clitic

\begin{tabular}{|c|c|c|c|c|c|}
\hline \multicolumn{3}{|c|}{ /h/-final roots } & \multicolumn{3}{|c|}{ Non-/h/-final roots } \\
\hline Gloss & Bare root & $1 \mathrm{~s}$ stem & Gloss & Bare root & $1 \mathrm{~s}$ stem \\
\hline 'to call' & $a^{3} k \tilde{1} h^{45}$ & $\mathrm{a}^{3} \mathrm{kin}^{43}$ & 'to stop' & $a^{4} n i^{43}$ & $a^{4} \operatorname{nif}^{4}$ \\
\hline 'back' & $\mathrm{t} \int \mathrm{i}^{3} \mathrm{rah}^{45}$ & $t \int i^{3} r a:^{43}$ & 'avocado' & su $u^{4} e^{43}$ & $\mathrm{si}^{3}-\mathrm{ru}^{4} \mathrm{neh}^{4}$ \\
\hline 'to run over' & $\operatorname{kah}^{3}$ & $\mathrm{ka}^{32}$ & 'to leave, appear' & $a^{3} \beta i_{i}^{32}$ & $a^{3} \beta i h^{3}$ \\
\hline 'to name (tr)' & $\mathrm{tu}^{2} \mathrm{ku} \mathrm{u}^{3} \mathrm{na} \mathrm{h}^{3}$ & $\mathrm{tu}^{2} \mathrm{ku} \mathrm{u}^{3} \mathrm{pna}:^{32}$ & 'salt' & jã: ${ }^{32}$ & tã $h^{3}$ \\
\hline
\end{tabular}

The type of tonal pattern that surfaces on the $1 \mathrm{~s}$ is dependent on the directionality of the morphological toggle. DiCanio (2016) describes these tonal processes in terms of tonal register, modified as in (14).

(14) $1 \mathrm{~s} / \mathrm{h} /$-insertion: Delink the vowel-final mora and reassociate to $/ \mathrm{h} /$. If the rightmost associated tone is: (a) [+Upper] and level (tones $/ 3 /$, /4/), replace with tone $/ 45 /$, (b) [+Upper] and complex (tone $/ 43 /$ ), delete tone $/ 3 /$.

Since contour tones (except for $/ 45 /$ ) do not surface on closed syllables in polysyllabic words (see $\$ 2.2 .1$ ), the insertion of $/ \mathrm{h} /$ to the right edge of the stem conditions deletion of the final tone $/ 3 /$. DiCanio $(2016,249)$ describes this as resulting from a rule of moraic delinking, shown in Figure 3. Insertion of a coda conditions contour simplification in polysyllabic words. ${ }^{21}$

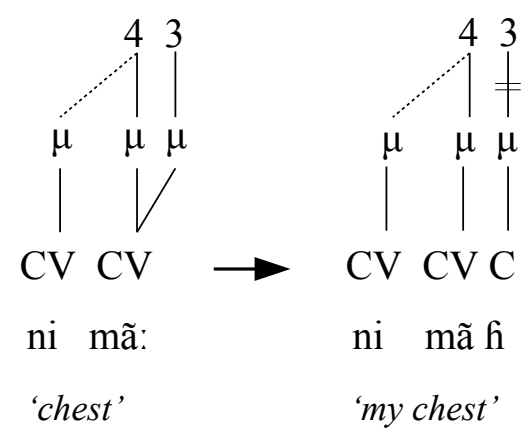

Figure 3: Moraic delinking with glottal insertion. Figure modified from DiCanio (2016).

The tonal changes associated with $/ \mathrm{h} /$-deletion must be stated differently in Itunyoso Triqui. For roots in this tonal subcategory with tone $/ 4 \mathrm{~h} /$ or $/ 45 \mathrm{~h} /$, the tone of the $1 \mathrm{~s}$ stem is usually $/ 43 /$, e.g. $/ \mathrm{na} \mathrm{f}^{45}$ / 'to wash' $\rightarrow$ [nã:i ${ }^{43}$ ' 'I wash.' If a root possesses tone $/ 3 \mathrm{~h} /$, the tone of the $1 \mathrm{~s}$ stem is $/ 32 /$, e.g. $/ \mathrm{ni}^{3} \mathrm{nah}^{3} /$ ' $^{\text {to be }}$ tired' $\rightarrow\left[\mathrm{ni}^{3} \mathrm{na:}^{32}\right]$ 'I am tired.' The output of $/ \mathrm{h} /$-deletion is the creation of a falling tone. This contrasts with the process of contour levelling associated with /h/-insertion. DiCanio (2016) similarly describes these tonal processes in terms of tonal register, which is modified as in (15). Figure 4 provides an autosegmental representation of the process.

\footnotetext{
${ }^{21}$ The same type of process applies to Itunyoso Triqui stems with a clitic glottal stop, e.g. the 1.DU clitic.
} 
(15) 1s /h/-deletion: Delete / $/$ / and reassociate its mora to the final vowel. If the rightmost associated tone is: (a) [+Upper, + High], insert and link tone $/ 3 /$ to the rightmost mora, (b) [+Upper, -High], insert and link tone $/ 2 /$ to the rightmost mora.

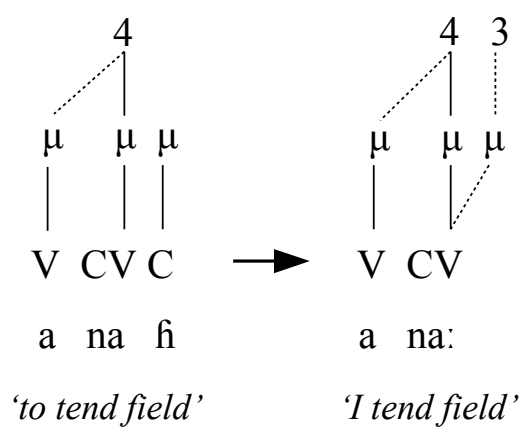

Figure 4: Moraic linking with glottal deletion.

For the purposes of the present paper, we have separated tonal processes occurring with roots taking a tone /4/ stem allomorph, shown in Table 14, and roots which undergo tonal insertion or deletion. While it is possible to analyze these output tonal processes as a single phenomenon after the application of initial stratum tonal rules, the roots are distinguished here on morphological grounds.

To summarize, three types of different tonal dependencies are observed within the data described here, but glottal toggling is the most consistent morphological exponent of the $1 \mathrm{~s}$ clitic in Itunyoso Triqui. First, for certain roots, glottal toggling is an independent morphological exponent from the tonal alternations. For stems with tone $/ 2 /$, as shown in Table 13 , the stem tone with the 1 s clitic lowers to $/ 1 /$. This occurs regardless of the directionality of the toggling process. Second, in low tone roots, glottal toggling is the sole morphological exponent of the 1s clitic. Third, a common pattern observed in Itunyoso Triqui is one where the directionality of the toggle determines the tonal alternations. Insertion of $/ \mathrm{h} /$ cooccurs with contour simplification (via right edge moraic deletion) or with the insertion of a high /45/ tone. Deletion of /h/ cooccurs with the creation of a falling tonal contour at the right edge of the stem. In general, these data demonstrate that the glottal toggling process associated with the 1s clitic is not specifically tied to a single tonal alternation or, in some cases, with any tonal alternation at all. Moreover, it is completely regular whereas many of the tonal alternations must be lexically specified.

\subsection{3ts clitic toggling}

Itunyoso Triqui possesses an alternation which marks recent, 3rd person discourse referents. This form is called the $3 r$ p person topic, or $3 \mathrm{TS}$. This form is often used to refer to inanimate entities or animate referents that have become the topic of the discourse (aforementioned entities), as shown in (16) and (17).

(16) Line 65, How does one prepare to weave by Carmen López González and Nieves López Guzmán (in DiCanio 2019)

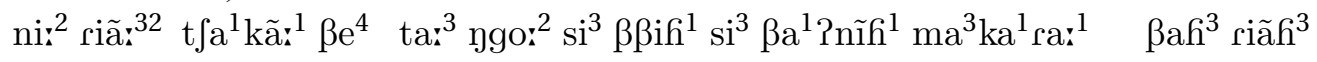

and where be.wide TOP that one or two or three hand.measures go above.3ts

'And where they are wide, then one or two or three hand measures go above it' 
(17) Line 8, Ethnobiology of “kkoj rukúj" by Francisco Fernández López (in DiCanio (2019))

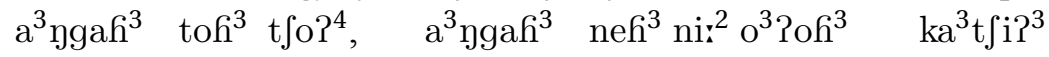

be.hurting some head.1.du be.hurting then, and hit/give.3ts fever

'(When) one's head hurts a bit, it's hurting then, and it gives (you) a fever'

In (16), a speaker is discussing how to measure the width of the loom (measured by the distance between the thumb and the pinky finger). The relational noun /riã: ${ }^{32} /$ 'face' is produced with the $3 \mathrm{TS}$ clitic (here, the loom), which involves / $/$ /-insertion, [riã $\left.h^{3}\right]$. In (17), the speaker is discussing the contexts for using a medicinal herb. The verb 'to hit/give' $/ \mathrm{oP}^{3} /$ is produced with the $3 \mathrm{TS}$ clitic (the referent is an non-specific illness), as $\left[\mathrm{o}^{3} \mathrm{Poh}^{3}\right]$. Like the $1 \mathrm{~s}$ clitic, the process involves toggling with the coda /h/. If the stem-final syllable has a coda $/ \mathrm{h} /$, it is deleted and the vowel is associated with the final mora. If it does not have a coda, $/ \mathrm{h} /$ is inserted and associated with the final mora of the stem.

However, unlike the $1 \mathrm{~s}$ clitic, the tonal shape of stems is entirely predictable based on the bare root's tonal register. In all cases the topical clitic involves insertion of tone $/ 3 /$. The tonal changes for deriving the $3 \mathrm{TS}$ forms are given below.

(18) If the stem-final syllable tone is a contour $(/ 45,43,32 /)$ or [+Upper] $(/ 4,3 /)$, replace it with $/ 3 /$; e.g. $\left./ \mathrm{t} \mathrm{i}^{3}{ }^{3} \mathrm{ninh}{ }^{4} /{\text { 'side' } \rightarrow\left[\mathrm{t} \mathrm{fi}^{3} \text { ?nĩ: }\right.}^{3}\right]$ 'the aforementioned's side.'

(19) If the stem-final syllable possesses a [-Upper] tone $(/ 2,1,31,13 /)$, append /3/ to the right edge; e.g. $/ \mathrm{ka}^{3} \mathrm{tĩ}^{1}{ }^{1}$ 'hip' $\rightarrow\left[\mathrm{ka}^{3} \mathrm{tĩh}{ }^{13}\right]$ 'the aforementioned's hip.'

Tonal changes which occur with the 3 TS clitic are sensitive to tonal register. If the stem-final tone is a low register level tone $(/ 2,1 /)$, tone $/ 3 /$ is appended to the right edge of the stem and does not condition tonal replacement. For all other stem-final tones $(/ 45,43,32,4 /)$, the tone is replaced with $/ 3 /$. For stems ending with tone $/ 3$ / (including /13/ and /3/), no tonal changes occur or, rather, $\varnothing$-derivation of tone occurs.

Examples of the toggling process for [+Upper] roots are given in Table 17. The stem-final tone is delinked and replaced with $/ 3 /$ regardless of the directionality of the /h/-toggling. Note that for roots with no associated pre-tonic tones, final tone replacement with $/ 3 /$ will iteratively spread onto the root via the Leftward association convention discussed in $\$ 2.2 .1$. Thus, one need not specify a separate tone spreading rule for the 3Ts clitic; leftward tonal association will replace all surface tones on a polysyllabic word. This is why, for instance, words like $/ a^{4} t \int \tilde{1}_{:}^{43} /$ 'to pass' seem to involve replacement of the entire stem's tone, $\left[\mathrm{a}^{3} \mathrm{t} \int \tilde{1}^{3}{ }^{3}\right]$ 'pass.3TS.' The penultimate syllable tone on the uninflected root is /4/ via leftward tonal association but tone $13 /$ in the stem inflected with the 3 TS clitic for the same reason.

Table 17: 3ts Clitic toggling and tonal replacement with /3/

\begin{tabular}{|c|c|c|c|c|c|}
\hline Gloss & Bare root & 3Ts stem & Gloss & Bare root & 3Ts stem \\
\hline 'to be above' & $\operatorname{ttah}^{45}$ & $\operatorname{tta:}^{3}$ & 'to take out' & $\mathrm{ri}^{32}$ & $\operatorname{rif}^{3}$ \\
\hline 'town' & $\mathrm{t} \int \mathrm{i}^{3} \mathrm{ja} \mathrm{h}^{45}$ & $t \int i^{3} j a a^{3}$ & 'to read' & $\mathrm{a}^{3} \mathrm{ja}^{32}$ & $a^{3} j_{a h^{3}}$ \\
\hline 'to buy' & $r a ̃ h^{4}$ & rã: ${ }^{3}$ & 'to eat' & $\mathrm{t} \int a:^{43}$ & $\mathrm{t} \int a h^{3}$ \\
\hline 'to be hurried' & $\mathrm{ra}^{4}$ ?jã $\mathrm{h}^{4}$ & $r a^{3}$ Pjã: ${ }^{3}$ & 'to pass' & $a^{4} t \int \tilde{1}^{43}$ & $a^{3} t \int \tilde{1} h^{3}$ \\
\hline 'paper' & jã $h^{3}$ & tã: ${ }^{3}$ & 'to come' & ?na? ${ }^{3}$ & $\operatorname{Pnah}^{3}$ \\
\hline 'to sleep' & $a^{3} \operatorname{toh}^{3}$ & $a^{3}$ to: $^{3}$ & 'to laugh' & $a^{3}$ pyga ${ }^{3}$ & $a^{3} \operatorname{lggah}^{3}$ \\
\hline
\end{tabular}

Identical to the pattern observed in Table 11 for the $1 \mathrm{~s}$ clitic, the $3 \mathrm{TS}$ produces two stem allomorphs for roots ending with a coda $/ \mathrm{P} /$ : either the $/ \mathrm{T} /$ is replaced by $/ \mathrm{h} /$ or a reduplicative $/ \mathrm{V} \mathrm{V} /$ form is appended. As above, if the tone on the root is [+Upper], the stem tone is replaced with $/ 3 /$. Many of the same words (but not all) which take the reduplicative allomorph with the $1 \mathrm{~s}$ clitic take this allomorph with the 3 Ts clitic. 
Table 18: Irregular 3ts marking on stems with coda /R/.

\begin{tabular}{|c|c|c|c|}
\hline Gloss & Bare root & Gloss & 3Ts stem \\
\hline 'to stink' & kĩ ${ }^{3}$ & 'he/she/they stink' & kĩ $\tilde{l}^{3} \tilde{i} h^{3}$ \\
\hline 'to look for' & na ${ }^{3}$ no? ${ }^{3}$ & 'he/she/they look for' & na $^{3}$ no $^{3}$ poh $^{3}$ \\
\hline 'to pick up (mass N.)' & $n a^{2} r a ̃ ?^{3}$ & 'he/she/they pick up' & $n a^{2} r \tilde{a}^{3} P a ̃ h^{3}$ \\
\hline 'tooth' & jã $P^{3}$ & 'his/her/their tooth' & jã $\tilde{a}^{3} \mathrm{a} \mathrm{h}^{3}$ \\
\hline
\end{tabular}

The tonal pattern observed on low register stems differs from the patterns shown in Tables 17 and 18. If the final tone on the root is $/ 2 /$ or $/ 1$ / (including the falling contour $/ 31 /$ ), tone $/ 3 /$ does not replace the stemfinal tone, but is appended onto the stem. If the stem is polysyllabic, only the tone on the final syllable is replaced (but the low register tone is retained on pre-tonic syllables). If the stem is monosyllabic, a complex contour is created. This produces tonotactic patterns which are normally ill-formed in Itunyoso Triqui (/313, 23/). Examples of this process are shown in Table $19 .^{22}$

Table 19: Insertion of tone /3/ with 3TS clitic marking

\begin{tabular}{|c|c|c|c|c|c|}
\hline Gloss & Bare root & 3TS stem & Gloss & Bare root & 3TS stem \\
\hline to be tall' & $\mathrm{t} \int \mathrm{a}^{1} \mathrm{ka} \tilde{a}^{1}$ & $\mathrm{t} \int \mathrm{a}^{1} \mathrm{ka} \mathrm{h}^{3}$ & 'shame' & na ${ }^{1} a f^{1}$ & $\mathrm{si}^{3}-n a^{1}{ }^{2} \mathrm{~s}^{3}$ \\
\hline 'illness' & $t \int \mathrm{i}^{3} \mathrm{Pi}^{1}$ & $s i^{3}-t \int i^{1} P i h^{3}$ & 'to spin around' & $\mathrm{a}^{3} \mathrm{ni}^{1} \mathrm{kah}^{1}$ & $\mathrm{a}^{3} \mathrm{ni}^{1} \mathrm{ka}^{3}$ \\
\hline 'with' & yga: ${ }^{1}$ & $\operatorname{ygah}^{13}$ & 'to be naked' & kã ${ }^{1}$ & $k a:_{:}^{13}$ \\
\hline 'to be short' & $\operatorname{tt} \int \mathrm{e}^{2}$ & $\mathrm{tt} \int \mathrm{eh} \mathrm{h}^{23}$ & 'knee' & $\mathrm{si}^{3} \mathrm{ru}^{1} \mathrm{ih}^{1}$ & $\mathrm{si}^{3} r \mathrm{u}^{1} \mathrm{i}^{3}$ \\
\hline 'head' & $t \int a_{i}^{31}$ & $\mathrm{t} \int a h^{313}$ & 'language' & snã $\tilde{a}^{4} \tilde{h}^{4}$ & $\operatorname{si}^{3}-$ snã ${ }^{1} P \tilde{a}_{:}^{3}$ \\
\hline
\end{tabular}

The tonal processes which apply to stems ending in a [-Upper] tone above interact with the application of potential aspect in verbal roots in Itunyoso Triqui. ${ }^{23}$ Verbs undergo an alternation in the potential aspect where either the entire stem tone is replaced with $/ 2 /$ or $/ 1 /$, or the initial syllable of the stem is replaced with tone $/ 2$ / (in vowel-initial verb stems). In both cases, the application of the 3Ts clitic morphology will not delink or replace tone $/ 2$. Examples of this interaction are shown in Table 20. It is compelling to consider the retention of lower register tones here as an example of a general constraint whereby the morphological tone of the potential aspect is realized. However, the examples in Table 19 above suggest that it is the tonal register and not its morphological role which conditions the different phonological behavior.

Table 20: Interaction between potential aspect tone /2/ with 3Ts clitic marking

\begin{tabular}{|c|c|c|c|c|c|}
\hline Gloss & Potential verb & 3Ts stem & Gloss & Potential verb & 3TS stem \\
\hline 'to be sold' & $\mathrm{ka}^{2} \mathrm{ne}^{2}$ & $\mathrm{ka}^{2} \mathrm{nef}^{3}$ & 'to boil' & $\mathrm{ku}^{2} \mathrm{jã} \mathrm{f}^{2}$ & $k u^{2} j \tilde{a}_{i}^{3}$ \\
\hline 'to sprout' & $k u^{2} t \int i^{2}$ & $k u^{2} t \int i h^{3}$ & 'to till' & $\mathrm{ka}^{2} \mathrm{nah}^{2}$ & $\mathrm{ka}^{2} \mathrm{na:} \mathrm{i}^{3}$ \\
\hline 'to eat' & $\mathrm{t} \int a:^{2}$ & $\mathrm{t} \int \mathrm{a} \mathrm{h}^{23}$ & 'to hit/give' & ko? ${ }^{1}$ & $\mathrm{ko}^{1} \mathrm{Poh}^{3}$ \\
\hline
\end{tabular}

There is one exception to the glottal toggling pattern with the $3 \mathrm{TS}$ clitic -- if the stem possesses a final tone /3/ on an open syllable, there are no morphological exponents of the $3 \mathrm{TS}$ clitic (no / $/$ /-insertion). However, deletion of $/ \mathrm{h} /$ is the exponent of the 3 TS clitic for stems possessing a final $/ \mathrm{Vh} /$ rime (with tone $/ 3 /$ ) and replacement/insertion of $/ \mathrm{h} /$ still serves as the exponent for stems with a /VP/ rime (with tone /3/). Table 21 provides examples of the $3 \mathrm{TS}$ clitic for stems with tone $/ 3 /$. The words in the left columns in Table 21 show

\footnotetext{
${ }^{22}$ Note that stems with tone $/ 31 /$ undergo low tone spreading prior to 3TS-insertion. The input stem shape for the 3TS clitic has tone $/ 1$ / in these cases. Also, clitic-modifed stems, like 'language', have a tone /1/ possessed stem (c.f. Table 7). Their surface 3Ts stems will have a $/ 1.3 /$ melody, as one can observe in Table 19.

${ }^{23}$ The morphology of verbal aspect is examined in more detail in (DiCanio 2020).
} 
no tonal or segmental changes associated with the $3 \mathrm{Ts}_{\text {clitic. }}{ }^{24}$ The words in the right columns show no tonal changes, but /h/-deletion or /h/-insertion has applied as it would with any other stem-final tone.

Table 21: 3ts clitic marking on tone $/ 3 /$ stems

\begin{tabular}{|c|c|c|c|c|c|}
\hline Gloss & Bare root & 3Ts stem & Gloss & Bare root & $3 \mathrm{TS}$ stem \\
\hline 'plough' & nne: ${ }^{3}$ & $\mathrm{si}^{3}-n e:^{3}$ & 'thorn' & ttã $h^{3}$ & $s i^{3}-t a i_{i}^{3}$ \\
\hline 'to be' & $\beta \tilde{l}_{i}^{3}$ & $\beta \tilde{1}^{3}$ & 'to $d o^{\prime}$ & $\operatorname{pjah}^{3}$ & Pja: ${ }^{3}$ \\
\hline$h a t^{\prime}$ & $\operatorname{ta}^{3} \beta \mathrm{ir}^{3}$ & $\operatorname{ta}^{3} \beta \mathrm{i}^{3}$ & 'to laugh' & $a^{3} \operatorname{pyga?^{3}}$ & $a^{3} \operatorname{lngah^{3}}$ \\
\hline `to peel & $a^{3} t \int i^{3}$ & $a^{3} t \int i i^{3}$ & 'to pray' & $n^{3} P \beta i h^{3}$ & $n a^{3} p \beta i_{i}^{3}$ \\
\hline
\end{tabular}

Apart from the exception mentioned here, the 3 TS clitic is marked via glottal toggling and the insertion of tone $/ 3 /$. The phonological behavior of tonal insertion is sensitive to the tonal register of the final syllable of the stem. Tone $/ 3 /$ is inserted on the right edge of stems with [-Upper] tones $(/ 31,2,1 /)$ and does not condition tonal replacement. Tone $/ 3 /$ replaces the entire stem tonal melody for all other tones. Unlike the $1 \mathrm{~s}$ clitic, the tonal rules associated with the $3 \mathrm{TS}$ clitic are phonologically regular. The most consistent exponent of the $3 \mathrm{TS}$ clitic across different stem tonal patterns is the application of the glottal toggling alternation.

\subsection{Quantifier nominalization}

Finally, adjectival quantifiers in Itunyoso Triqui undergo a derivational process which produces nominalized forms. Included within this class are the numbers 1-6 and more general quantifiers like 'many', 'half', 'much', etc. Adjectival quantifiers in Itunyoso Triqui require a noun, e.g. $/ \mathrm{ygo:}^{2}$ sĩ $^{3} /$ 'one/a child', whereas nominalized forms never occur with an overt noun, e.g. $/$ ggoh $^{13} /$ 'one of them', */ggoh ${ }^{13} \sin ^{3} /$. The derivational process involves the same glottal toggling observed with the 1s and 3TS clitics. Like the 3TS clitic, the process also involves the application of a specific tone - in this case, the low rising tone /13/. Examples are given in Table 22.

Table 22: Quantifier nominalization in Itunyoso Triqui

\begin{tabular}{|c|c|c|c|c|c|}
\hline Gloss & Adjective & Nom. form & Gloss & Adjective & Nom. form \\
\hline one' & ygo: ${ }^{2}$ & ngof ${ }^{13}$ & $t w o^{\prime}$ & $\beta \beta \mathrm{ih}^{1}$ & $\beta \beta \mathrm{i}^{13}$ \\
\hline five' & $\tilde{\mathrm{u}} \mathrm{P}^{2} \tilde{\mathrm{u}} \mathrm{P}^{2}$ & $\tilde{u}^{1} P \tilde{u} h^{3}$ & 'three' & $\beta \mathrm{a}^{1}$ ?nif $^{1}$ & $\beta \mathrm{a}^{1} \mathrm{ni}^{3}$ \\
\hline$s i x$ & $\beta \mathrm{a}^{1} \mathrm{tã}^{1}$ & $\beta \mathrm{a}^{1}$ tã $^{3}$ & four' & kã $\tilde{l}^{1}\left\{\tilde{h} h^{1}\right.$ & kã $\tilde{a}^{1} \tilde{a}^{3}$ \\
\hline 'none' & $\mathrm{a}^{1}$ Pygo: ${ }^{3}$ & $a^{1}$ pygoh ${ }^{3}$ & 'half (w/count $N)^{\prime}$ & $a^{2} n e f^{2}$ & $a^{1} n e^{3}$ \\
\hline
\end{tabular}

There is a close relationship between the derivational patterns shown above and the morphophonology of the 3 TS clitic. Certain quantifiers may be inflected by the 3 TS clitic and have the same nominalized reading, e.g. $/ \mathrm{a}^{4} \mathrm{ygo:}^{43} /$ 'another' vs. [a $\mathrm{a}^{3} \mathrm{ygoh}^{3}$ ] 'another of them.' For quantifiers with tone $/ 1 /$, the two patterns are indistinguishable. For those quantifiers with tone $/ 2 /$, the tonal alternation with $/ 13 /$ is unique to the derivational process described here.

\section{Discussion}

\subsection{Glottal toggling as an exchange rule}

Does the glottal coda alternation found with the $1 \mathrm{~s}, 3 \mathrm{TS}$, and quantifier nominalization reflect a morphophonological exchange rule? The three empirical criteria outlined in $\$ 1.1$ are (1) productivity, (2) dominance, and

\footnotetext{
${ }^{24}$ Geminate-initial words degeminate when the possessive prefix is applied, but this process is associated with prefixation more generally and not with cliticization.
} 
(3) morphosyntactic uniformity. Considering the first criterion, the alternation is productive. The two exceptions to its application are the small class of $22 / 3 /$-final words which take a reduplicative stem form with the $1 \mathrm{~s}$ and 3 TS clitics (c.f. Tables 11 and 18), and the words with a final open syllable and tone $/ 3 /$ which undergo Ø-derivation with the 3 TS (c.f. Table 21), the latter of which is a principled exception. All other roots in Itunyoso Triqui undergo the toggling process. ${ }^{25}$

The presence of the glottal toggling pattern in multiple morphological contexts in Itunyoso Triqui also stands in contrast to de Lacy's discussion of the voicing alternation with the Dholuo plural in de Lacy (2012). For Dholuo, de Lacy argues that several morphological alternations require that the final obstruent of a vowel-final root be specified as [-voice]. This is treated as evidence which supports a devoicing analysis of Dholuo vowel-final stems instead of the exchange rule analysis for [voice]. The presence of a devoicing process elsewhere in the grammar suggests that the devoicing analysis is the more parsimonious analysis. Yet, in Itunyoso Triqui, the same glottal exchange rule is found in multiple morphological alternations in the grammar. The pattern is not only productive within one morphological alternation, but it is productive in several. This supports the idea that an exchange rule is the active alternation in the language.

The second criterion, dominance, is also satisfied by the Itunyoso Triqui data. The glottal exchange rule is the only consistent morphological exponent for both the 1s and 3TS morphemes. Tonal changes, either at the right edge of the stem or replacive tonal rules, accompany both morphemes. For the $1 \mathrm{~s}$ clitic, the tonal alternations are predictable for roots with certain tonal types, but suppletive stem tonal alternations are necessary for a large number of words. For the $3 \mathrm{TS}$ clitic, the tonal alternations are entirely predictable based on the stem tone. Moreover, the type of tonal change with the $1 \mathrm{~s}$ is predictable based on the directionality of the exchange rule. Recall that tonal raising is associated with $/ \mathrm{h} /$-insertion for roots with upper register tones, e.g. / $\mathrm{ra}^{3} \mathrm{~Pa}^{3} /{ }^{3}$ 'hand' $\rightarrow\left[\mathrm{ra}^{3} \mathrm{Pah}^{5}\right]$ ' $\mathrm{my}$ hand', but with the creation of a falling contour with/h/-deletion, e.g. $/$ nneh $^{3} /$ 'dream' $\rightarrow\left[\mathrm{si}^{3}-\mathrm{ne:}^{32}\right]$ 'my dream'. In this way, the glottal exchange rule is not only the more consistent morphological exponent, but it predicts the type of tonal alternation that one observes on Itunyoso Triqui stems. Finally, for both the $1 \mathrm{~s}$ and $3 \mathrm{TS}$ clitics, there are roots for which no tonal alternation occurs. ${ }^{26}$ Each of these observations is consistent with the idea that the glottal alternation in Itunyoso Triqui is a dominant process in the morphemes where it occurs.

The final criterion, morphosyntactic uniformity, is also satisfied by the Itunyoso Triqui data. If the toggling process were non-uniform, one would predict a morphological bias where one side of the process applied. For instance, in the analysis of Kumeyaay and Shilluk, de Lacy (2012) argues that long vowel shortening is uncommon/marked relative to the more frequent process of short vowel lengthening. The frequency imbalance between the two types of alternations is taken as evidence that the alternation is non-uniform. Yet, in Itunyoso Triqui, there is no tendency for /h/-insertion or deletion to apply more often to a specific part of speech than the other. In other words, the sole criterion for distinguishing between roots possessing a coda $/ \mathrm{h} /$ and those lacking one is phonological. Roots possessing a coda / $\mathrm{h} /$ are not rare in the Itunyoso Triqui lexicon. Table 23 shows the frequency of words of each rime type in Itunyoso Triqui. Roots with a final open syllable are most common in Itunyoso Triqui (and slightly more common in nouns than in verbs), but roots with a coda / $\mathrm{h} /$ are frequent. Moreover, the frequencies of rime types in the lexicon are roughly equivalent for different parts of speech (nouns vs. verbs). There are neither phonological biases or part of speech biases which favor insertion or deletion in the glottal toggling process.

\footnotetext{
${ }^{25}$ While not discussed in the present paper, Spanish loanwords also undergo a rule of $/ \mathrm{h} /$-insertion in the expected contexts. However, since Spanish lacks codas /, $\mathrm{h} /$ and all loanwords are vowel-final, insertion is the only possible process that may occur, i.e. $/ \mathrm{lu}^{4} \mathrm{ta:}^{43} /\left(\right.$ Sp. pelota) 'ball' $\rightarrow / \mathrm{si}^{3}-\mathrm{lu}^{4} \mathrm{tah}^{4} /$ 'my ball.'

${ }^{26}$ This last point is particularly relevant for the $3 \mathrm{TS}$ clitic, since the insertion of tone $/ 3$ / varies less for this morpheme than tonal rules for the $1 \mathrm{~s}$ clitic.
} 
Table 23: Lexical frequency of rime types by part of speech

\begin{tabular}{llll}
\hline Final rime & Frequency in verbs & Frequency in nouns & Frequency in lexicon \\
\hline Vh & $156 / 443=35.2 \%$ & $202 / 654=30.9 \%$ & $558 / 1611=35 \%$ \\
V? & $97 / 443=21.9 \%$ & $94 / 654=14.4 \%$ & $281 / 1611=17 \%$ \\
V: & $188 / 443=42.4 \%$ & $358 / 654=54.7 \%$ & $772 / 1611=48 \%$ \\
\hline
\end{tabular}

Finally, note that the glottal toggling process systematically produces surface-level homophony between uninflected and inflected forms. The $1 \mathrm{~s}$ form of the root $/ \mathrm{a}^{4} \mathrm{ni}^{4} /$ 'to get dirty' is [a $\left.\mathrm{a}^{4} \mathrm{ni}^{43}\right]$. The $1 \mathrm{~s}$ form of the root $/ \mathrm{a}^{4} \mathrm{ni}^{43} /$ 'to stop' is $\left[\mathrm{a}^{4} \mathrm{ni}^{4}{ }^{4}\right]$. Alternations within the same part of speech may produce homophony within the same class. These data show that there is no morphosyntactic criterion for distinguishing between stems which undergo /h/-insertion or /h/-deletion. The sum of the evidence presented here, examined in relation to the same empirical criteria that de Lacy (2012) uses to argue that Dholuo does not have a morphophonological exchange rule, precisely argues that the Itunyoso Triqui glottal alternation is indeed a morphophonological exchange rule.

\subsection{Serialist vs. Parallelist approaches to Triqui glottal toggling}

\subsubsection{The serialist approach}

Serialist phonological approaches can avoid the necessity for an exchange rule since multiple derivational strata may permit local non-exchange mappings. Assume, for instance, that the toggling process is represented as a concatenative suffix /-h/. We may establish two rules and a constraint to derive correct surface representations of several Triqui forms, shown below in (20) - (22).

(20) Stress Augmentation: Add a mora to a stressed syllable.

(21) OCP-segment: $* \mathrm{C}_{i} \mathrm{C}_{i}$ ('i' indicates identity).

(22) Root-final C-deletion: $\mathrm{C} \rightarrow \varnothing / \ldots]$ root

One can derive the correct surface representations for most Triqui forms, as shown in Table 24. The stress augmentation rule is motivated by the prosodic minimality requirement in the language demanding that all root-final syllables be bimoraic (see $\S 2.2$ ). Because the toggling process unfolds across multiple levels, there is no local morphophonological exchange rule.

Table 24: Glottal toggling via serial derivation

\begin{tabular}{|c|c|c|c|}
\hline & $\mathrm{a}^{4} \mathrm{ni}^{43}$ 'to stop' & $a^{4} n i \tilde{h} h^{4}$ to dirty oneself' & $\mathrm{a}^{3}$ nĩ $^{3}$ 'to separate' \\
\hline -/h/ affixation & $\mathrm{a}_{\mu}^{4} \mathrm{n} \tilde{\mathrm{i}}_{\mu}^{4}-\mathrm{h}$ & Blocked by OCP & $\mathrm{a}_{\mu}^{4} \mathrm{n} \tilde{\mathrm{r}}_{\mu}^{4} \mathrm{P}-\mathrm{h}$ \\
\hline Root-final C-deletion & N/A & $\mathrm{a}_{\mu}^{4} \mathrm{ni}_{\mu}^{4}$ & $\mathrm{a}_{\mu}^{4} \mathrm{n} \tilde{\mathrm{l}}_{\mu}^{4}-\mathrm{h}$ \\
\hline Stress augmentation & $\mathrm{a}_{\mu}^{4} \mathrm{ni}_{\mu}^{4} \mathrm{~h}_{\mu}$ & $\mathrm{a}_{\mu}^{4} \mathrm{ni}_{\Perp}^{43}$ & $\mathrm{a}_{\mu}^{4} \mathrm{ni}_{\mu}^{4} \mathrm{~h}_{\mu}$ \\
\hline SR & $\mathrm{a}_{\mu}^{4} \mathrm{ni}_{\mu}^{4} \mathrm{~h}_{\mu}$ & $\mathrm{a}_{\mu}^{4} \mathrm{nin}_{\mu \mu}^{43}$ & $\mathrm{a}_{\mu}^{4} \mathrm{ni}_{\mu}^{4} \mathrm{~h}_{\mu}$ \\
\hline
\end{tabular}

This analysis is not without its own problems though. First, it fails to correctly derive the reduplicative pattern found with certain / $/$ /-final roots. While the roots which undergo reduplication are rarer than those which do not ( $20 \%$ of the / $/$ /-final roots), they can not be correctly derived here. Second, it is currently unclear where tonal association takes place. The word 'to separate' is an IDCM root, so the associated stem tone which occurs with the $1 \mathrm{~s}$ clitic is /4/. IDCM tonal stem formation must take place alongside concatenation. However, the rules for tonal insertion and deletion (see (14) and (15), above) must take place 
at a later stage. It is beyond the scope of the current paper to provide a comprehensive analysis of this, though these different tonal rules must be sensitive to different types of morphological boundaries. This is problematic for phonological approaches requiring a strict separation between morphology and phonology but it is uncontroversial for theories involving multiple strata where morphology and phonology interleave, such as Lexical Morphology and Phonology (Kiparsky 1985), Stratal Optimality Theory (Kiparsky 2000), and cophonology theory (Inkelas \& Zoll 2007) (for an overview, see Ch.7 of Inkelas (2014)). While the serial approach is problematic in these ways, there is no morphophonological exchange rule at any individual stratum in the serial derivation. In fact, the root-final consonant deletion rule is not sensitive to glottal features at all.

\subsubsection{The parallelist approach}

A parallelist approach to the same data in classical Optimality Theory (Kager 1999; Prince \& Smolensky 1993) necessarily involves a morphophonological exchange rule and contradictory mappings. To begin to illustrate this, we may define four phonological constraints for Itunyoso Triqui in addition to utilizing the OCP-segment constraint in (21). These are given below in (23) - (26).

(23) Stress-Bin: A stressed syllable is bimoraic.

(24) DEP-IO( $\mu$ ): Do not epenthesize moras.

(25) MAX-IO(segment): Do not delete segments.

(26) $* \mathrm{Cl}_{\text {root }}$ : Avoid a root-final C.

The constraint in (23) is analogous to the stress augmentation rule in (20). Though stated as a stressrelated constraint here, it is also functionally equivalent to a positional binarity constraint, e.g. FIN- $\sigma$-BIN (c.f. Kager 1999). Both possible constraints specify that final syllables in roots must be bimoraic, as per the descriptive discussion in $\$ 2.2$. Both DEP and MAX constraints are previously established in the literature (McCarthy \& Prince 1995). The constraint in (26), $\left.{ }^{*} \mathrm{C}\right]_{\text {root }}$, is a morphologically-indexed constraint specifying that root-final syllables may not have codas. A sample tableau of a form involving glottal deletion (for the input word $/ \mathrm{a}^{3} \mathrm{ni}^{3} /$ ' to separate' is given in (27) below.

\begin{tabular}{|c|c|c|c|c|c|c|}
\hline $\mathrm{a}_{\mu}^{3} \mathrm{ni}_{\mu}^{3} \mathrm{P} \mid \mathrm{f}$ & $\left.{ }^{*} \mathrm{C}\right]_{\text {root }}$ & OCP-SEGMENT & STRESS-BIN & DEP-IO $(\mu)$ & MAX-IO(SEGMENT) & NoCoDA \\
\hline a. $a_{\mu}^{4} n \tilde{n}_{\mu}^{4} P \mid \hat{~}$ & $* !$ & & * & & & * \\
\hline b. $a_{\mu}^{4} n \tilde{r}_{\mu}^{4} \mid \mathrm{h}$ & & & $* !$ & & * & * \\
\hline 㶲 c. $a_{\mu}^{4} n_{1}^{4}{ }_{\mu}^{4} \mathrm{~h}_{\mu}$ & & & & * & * & * \\
\hline d. $\mathrm{a}_{\mu}^{4} n^{4} \tilde{r}_{\mu \mu}^{4}$ & & & & * & $* * !$ & \\
\hline e. $a_{\mu}^{4} n \tilde{1}_{\mu}^{4}$ & & & $* !$ & & $* *$ & \\
\hline
\end{tabular}

The optimal candidate in this analysis is the form which crucially both satisfies the root-final consonant deletion rule and the constraint ensuring final syllable bimoraicity. This same constraint ranking works for input forms involving glottal insertion. A tableau of the word / $/ \mathrm{a}^{4} \mathrm{ni}^{43} /$ 'to stop' is given below in (28).

\begin{tabular}{|c|c|c|c|c|c|c|}
\hline $\mathrm{a}_{\mu}^{4} \mathrm{n} \tilde{r}_{\mu}^{43} \mid \mathrm{h}$ & $\left.{ }^{*} \mathrm{C}\right]_{\text {root }}$ & OCP-SEGMENT & STRESS-BIN & DEP-IO $(\mu)$ & MAX-IO(SEGMENT) & NoCoDA \\
\hline a. $\mathrm{a}_{\mu}^{4} \mathrm{ni}_{\mu}^{4} \mid \mathrm{h}$ & & & $* !$ & & & * \\
\hline b. $a_{\mu}^{4} n_{1}^{4}{ }_{\mu}^{4} \mid \mathrm{h}_{\mu}$ & & & & * & & * \\
\hline c. $\mathrm{a}_{\mu}^{4} \mathrm{n}_{1}^{4} \tilde{r}_{\mu \mu}^{4}$ & & & & * & $* !$ & \\
\hline d. $a_{\mu}^{4} n \tilde{n}_{\mu}^{4}$ & & & $* !$ & & & \\
\hline
\end{tabular}


However, the same constraint ranking produces the incorrect output form when we examine words which undergo glottal deletion. A tableau of the word $/ \mathrm{a}^{4} \mathrm{ni}^{4} \mathrm{~h}^{4} /$ 'to dirty oneself' is given below in (29). The predicted candidate wins because nothing compels the deletion the clitic pronoun. Instead, the candidate which incurs two violations of MAX-IO(segment) is the observed output form.

$$
/ \mathrm{a}_{\mu}^{4} \tilde{1}_{\mu}^{4} \mathrm{~h} \mid \mathrm{h} / \rightarrow\left[\mathrm{a}_{\mu}^{4} \mathrm{ni}_{\mu \mu}^{43}\right] \text { 'I dirty myself' }
$$

\begin{tabular}{|c|c|c|c|c|c|c|}
\hline $\mathrm{a}_{\mu}^{4} \mathrm{ni}_{\mu}^{4} \mathrm{~h} \mid \mathrm{h}$ & $\left.{ }^{*} \mathrm{C}\right]_{\text {root }}$ & OCP-SEGMENT & STRESS-BIN & DEP-IO $(\mu)$ & MAX-IO(SEGMENT) & NoCoDA \\
\hline a. $\mathrm{a}_{\mu}^{4} \mathrm{ni}_{\mu}^{4} \mathrm{~h} \mid \mathrm{h}$ & $* !$ & * & * & & & $*$ \\
\hline b. $\mathrm{a}_{\mu}^{4} \mathrm{ni}_{\mu}^{4} \mid \mathrm{h}$ & & & $*$ & & $*$ & $*$ \\
\hline c. $\mathrm{a}_{\mu}^{4} \mathrm{ni}_{\mu}^{4} \mathrm{~h} \mid$ & $* !$ & & $*$ & & $*$ & $*$ \\
\hline है. $a_{\mu}^{4} n \tilde{n}_{\mu}^{4} \mid \mathrm{f}_{\mu}$ & & & & * & * & * \\
\hline e. $\mathrm{a}_{\mu}^{4} \mathrm{n} \tilde{1}_{\mu \mu}^{43}$ & & & & * & $* * !$ & \\
\hline
\end{tabular}

It is in this last tableau in (29) that we observe the computational contradiction in the parallelist account. The optimal candidates in the first two tableaux require deletion of the root final consonant and avoid a violation of the constraint in (26). Dispreferred candidates are those which violate MAX-IO(segment) more than once. However, the observed candidate in the final tableau (with glottal deletion) necessarily incurs two violations of MAX-IO(segment). The parallelist account cannot generate the correct output forms since it requires an exchange to take place within a single stage and therefore treats the Itunyoso Triqui glottal toggling process as a morphophonological exchange rule. Morphophonological exchange rules cannot be modelled in classical parallelist models of OT.

\subsubsection{General issues for formal analyses}

Morphophonological exchanges are a challenge to classical, parallelist optimality-theoretic approaches because they necessarily involve a markedness paradox. There are several types of approaches within Optimality Theory which might be used to formalize the toggling process. All must require distinct correspondences either within the morphological component of the grammar, e.g. RealizeMorph (Kurisu 2001; Walker 2000) or be inherent to a morphological stratum of the grammar, e.g. cophonology theory (Inkelas \& Zoll 2007). ${ }^{27}$

Another possibility that has not been examined in the current paper is a non-concatenative solution. That is, one might model the toggling process as a featural exchange mapping that is sensitive to the features on the final syllable of the stem, i.e. stems with final [+SPREAD GLOTTIS] take a [-SPREAD GLOTTIS] feature specification, while those with a final [-SPREAD GLOTTIS] specification take a final [+SPREAD GLOTTIS] feature specification. It is important to note that this type of phonologically-conditioned process morphology is not possible in item-based theories of morphology, but we question whether an adherence to item-based theories is too restrictive given the empirical data presented here.

A seemingly promising approach to the toggling process is the notion that segments in input representations in exchange mappings may be marked by PRESENCE features indicating disparities in correspondence (Nyman \& Tesar 2019). This possibility permits processes of segmental deletion to be encoded and learned in a formal phonological grammar and results in paradigmatic effects observed in phonological systems (c.f. Steriade 2000). However, this approach is based specifically on the notion of output-driven mappings. Exchanges like [-SPREAD GLOTTIS] $\rightarrow$ [+SPREAD GLOTTIS] and [+SPREAD GLOTTIS] $\rightarrow$ [-SPREAD GLOTTIS], like chain shifts, are not output-driven (Tesar 2014, 23).

Any particular formal approach to the Triqui toggling process would also need to capture (a) stratal effects on tonal derivation such as those shown in Figure 9 and (b) morpheme-specific tonal changes which are sensitive to different types of tonal features. Tonal changes have been specifically excluded in $\S 3.2$, but they encode morpheme-specific information independently from the glottal toggling processes and they

\footnotetext{
${ }^{27}$ As discussed in Alderete (2001) and Horwood (2000), related constraints within phonological theory, like DistinctForm, are incapable of describing morphologically-induced allomorphy and are excluded here.
} 
interact with tonal changes related to verbal aspect. Thus, many verbs lack a single tonal alternation for the $1 \mathrm{~s}$ clitic - it can be marked via tonal lowering $(/ 2 / \rightarrow / 1 /)$ in the potential aspect or by tonal raising $(/ 3 / \rightarrow$ $/ 45 /$ ) in the perfective aspect (see Table 9 and DiCanio 2020).

Moreover, any formal approach would also have to be able to account for non-toggling morphology involving glottal features as well. While we have not discussed such processes here, Itunyoso Triqui possesses several non-toggling morphological processes which involve tone. For instance, emphatic marking on nouns involves appending a coda glottal stop and tone $/ 4 /, /-4 ? /$. This tone will replace the stem tone if the stem tone is [+Upper]. If it is [-Upper], the tone is appended to the root but does not spread leftward. This behavior is similar to the pattern observed with the 3 TS clitic in Table 19. However, no segmental toggling takes place - the glottal stop here links to the final mora of the final syllable. For certain alternations like the $1 \mathrm{~s}$, tonal changes interact with the segmental changes, while for others, they are distinct. Thus, glottal exchange rules occur just within one area of the Itunyoso Triqui grammar. Phonological theory should seek to account for phonological generalizations at the level of the language, not just individual alternations (Kiparsky 2000; Vaux 2008).

A remaining, open question here is the extent to which the alternations in the Triqui toggling process are best described as exchange mappings or exchange rules. Two components are necessary for a morphophonological exchange rule: a circular featural exchange mapping and a single stratum where such an exchange takes place. Within any theory permitting multiple strata for deriving surface representations/outputs, morphophonological exchange rules may not be necessary at a local level. After all, subsequent derivations are blind to previous ones, i.e. derivations of the shape $/ \alpha />\beta>[\alpha]$ are possible. Yet within parallelist approaches, the distinction between an exchange mapping and an exchange rule does not matter - both create a computational contradiction. The question of whether a exchange rule occurs is therefore dependent on the formal approach to the toggling process. We do not seek to resolve this particularly thorny question in the current paper, but leave it open for future analysis.

\subsection{Clitic morphophonology in Triqui dialects}

Clitic morphophonology is a robust area of research within Oto-Manguean morphological and phonological systems (c.f. Palancar \& Léonard 2016 for a recent overview). Tone has a very high functional load within these languages and is implicated at many morphological levels. ${ }^{28}$ Simultaneously, glottal consonants and non-modal phonation types are often contrastive and orthogonal to tone (DiCanio \& Bennett 2020; Silverman 1997). Within Itunyoso Triqui clitics we observe the independence of each of these phonological contrasts. Glottal toggling is an independent morphological exponent from the type of tonal process with which it cooccurs. For instance, certain IDCM stems may take a tone /4/ stem while others condition a high tone in the tonic syllable only. Tonal and glottal phonologies interact where phonological co-occurrence restrictions and tonal well-formedness principles determine the specific type of surface lexical tone which is permitted. The data and analyses here also demonstrate the interaction between stem tone formation at an initial stratum in morphological derivation and subsequent tonal processes which apply with specific clitic morphologies. The fact that both levels involve tonal changes, only one of which is conditioned by a particular clitic, has made the analysis of Triqui clitic morphophonology particularly challenging (c.f. Longacre 1959 on similar issues which arise in the analysis of Chicahuaxtla Triqui clitics).

There are some substantial differences in clitic morphology between Triqui variants. The glottal exchange rule does not occur in Copala Triqui (Hollenbach 1984, 334). Instead, /-h/ is appended to all stems as one exponent of the $1 \mathrm{~s}$ clitic (the other exponent being different tonal alternations). However, like Itunyoso Triqui, certain stems in Copala Triqui with final /V?/ rimes receive a reduplicative $/ \mathrm{Vh} /$ allomorph. In Chicahuaxtla Triqui, an /h/ toggling process similar to the one found in Itunyoso Triqui occurs for the $1 \mathrm{~s}$ and the 3s.FEM clitics (Longacre 1959; Good 1979), but with a different set of tonal alternations. How the

\footnotetext{
${ }^{28}$ In Mixtecan languages, negation and tone also interact at higher syntactic levels (Hollenbach 1976).
} 
morphophonological exchange rule in Itunyoso Triqui evolved remains an area of open research, however.

\subsection{Concluding remarks}

The data presented here provide the first comprehensive description of the glottal toggling process in Itunyoso Triqui. The glottal exchange rule (or mapping) is the primary phonological exponent of several morphological processes, such as first person singular and third person topic cliticization; and a minor pattern of quantifier nominalization. The first person singular is also marked via processes of tonal change on the stem, some of which are predictable by stem tone but others which are lexically specified. The third person topic and quantifier nominalization processes are accompanied by distinct and regular processes of tonal change on roots.

Work set within classical, parallelist Optimality Theory has argued against the existence of morphophonological exchange rules (de Lacy 2012; Wunderlich 2012). Such rules involve a single featural exchange which takes place in a single stage/stratum. As such, they necessarily involve a markedness paradox. Previous empirical evidence against such rules has argued that they have limited productivity, they do not reflect the dominant morphological exponent of an alternation, and they are not morphosyntactically uniform (noncircular semantic change). The evidence reviewed in $\S 2$ and 3.1 demonstrate that the Itunyoso Triqui glottal toggling process is productive, dominant, and morphosyntactically-uniform. By solely these criteria, the process seems to be a morphophonological exchange rule.

Previous work has doubted the existence of such processes in human languages and, as a result, researchers have not needed to model them within a phonological grammar (de Lacy 2012; Wunderlich 2012). The conclusion that attested exchange rules (such as in Dholuo) should be analytically bifurcated into separate morphophonological operations is not under examination in the current work. However, in-depth linguistic work on understudied and endangered languages, as reflected here, is both important and likely a promising area for discovering unique morphophonological operations. ${ }^{29}$ Typological claims regarding types of morphological processes are best evaluated through a combination of both broad surveys of languagespecific patterns and careful investigations into such patterns within individual languages.

\section{Abbreviations}

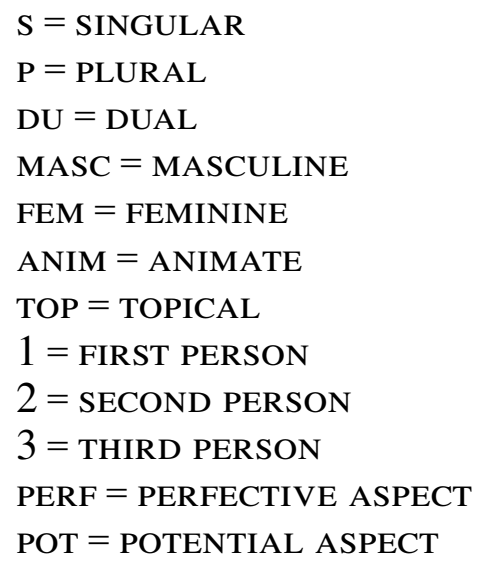

\section{References}

Alderete, John. 2001. Dominance effects as transderivational anti-faithfulness. Phonology 18(2). 201253. https://doi.org/10.1017/S0952675701004067.

\footnotetext{
${ }^{29}$ For instance, another example of toggling morphophonology is found in Choguita Rarámuri pluractionals (Caballero 2008).
} 
Baerman, Matthew. 2007. Morphological reversals. Journal of Linguistics 43. 33-61. https://doi.org/10.1017/S0022226706004440.

Bermúdez-Otero, Ricardo. 2017. Stratal phonology. In S. J. Hannahs \& Anna Bosch (eds.), The syllable in optimality theory. Abingdon: Routledge. https://doi.org/10.4324/9781315675428-5.

Broadwell, George Aaron \& Lauren Clemens. 2017. Inflectional change in Copala Triqui. Talk presented at the Society for the Study of the Indigneous Languages of the Americas (SSILA) Annual Meeting, Austin, TX.

Caballero, Gabriela. 2008. Choguita Raramuri (Tarahumara) phonology and morphology. Berkeley, CA: University of California dissertation.

Clements, G. N., Alexis Michaud \& Cédric Patin. 2011. Do we need tone features? In John A. Goldsmith, Elizabeth V. Hume \& Leo Wetzels (eds.), Tones and features: Phonetic and phonological perspectives (Studies in Generative Grammar 107). 3-24. Berlin: De Gruyter.

DiCanio, Christian. 2008. The phonetics and phonology of San Martín Itunyoso Trique. Berkeley, CA: University of California dissertation.

DiCanio, Christian. 2010. Itunyoso Trique. Journal of the International Phonetic Association 40(2). $227-$ 238. https://doi.org/10.1017/S0025100310000034.

DiCanio, Christian. 2012a. Coarticulation between tone and glottal consonants in Itunyoso Trique. Journal of Phonetics 40. 162-176.

DiCanio, Christian. 2012b. The phonetics of fortis and lenis consonants in Itunyoso Trique. International Journal of American Linguistics 78(2). 239-272. https://doi.org/10.1086/664481.

DiCanio, Christian. 2014. Triqui tonal coarticulation and contrast preservation in tonal phonology. In Ryan Bennett, Rikker Dockum, Emily Gasser, Dolly Goldenberg, Ryan Kasak \& Patrick Patterson (eds.), Proceedings of the Workshop on the Sound Systems of Mexico and Central America. New Haven, CT: Department of Linguistics, Yale University.

https://ling.yale.edu/sites/default/files/files/ssmca-proceedings/papers/DiCanio-2014-TriquiSSMCA.pdf.

DiCanio, Christian. 2016. Abstract and concrete tonal classes in Itunyoso Trique person morphology. In Enrique Palancar \& Jean-Léo Léonard (eds.), Tone and inflection: New facts and new perspectives (Trends in Linguistics Studies and Monographs 296). 225-266. Berlin: De Gruyter.

DiCanio, Christian. 2019. Itunyoso Triqui collection of Christian DiCanio. The Archive of the Indigenous Languages of Latin America. https://ailla.utexas.org/islandora/object/ailla\%3A243683.

DiCanio, Christian. 2020. Aspecto verbal en triqui de Itunyoso. In Michael Swanton, Marcela San Giacomo Trinidad \& Fidel Hernández Mendoza (eds.), Estudios fonológicos de idiomas mixtecanas. Mexico City: Universidad Nacional Autónoma de México.

DiCanio, Christian \& Ryan Bennett. 2020. Prosody in Mesoamerican languages. In Carlos Gussenhoven \& Aoju Chen (eds.), The Oxford handbook of language prosody. Oxford: Oxford University Press.

DiCanio, Christian \& Richard Hatcher. 2018. On the non-universality of intonation: evidence from Triqui. Journal of the Acoustical Society of America 144. 1941. https://doi.org/10.1121/1.5068494.

DiCanio, Christian, Basileo Martínez Cruz, Benigno Cruz Martínez \& Wilibaldo Martínez Cruz. 2018. Diccionario bilingüe - triqui de itunyoso y castellano.

Elliott, A. Ray, Jerold A. Edmondson \& Fausto Sandoval Cruz. 2016. Chicahuaxtla Triqui. Journal of the International Phonetic Association 46(3). 351-365. https://doi.org/10.1017/S0025100315000389.

Good, Claude. 1979. Diccionario triqui (Serie de Vocabularios Indigenas 20). Oaxaca, MX: SIL Mexico.

Gordon, Matthew \& Timo Roettger. 2017. Acoustic correlates of word stress: A cross-linguistic survey. Linguistics Vanguard 1. 20170007. https://doi.org/10.1515/lingvan-2017-0007.

Hernández Mendoza, Fidel. 2017. Tono y fonología segmental en el triqui de chicahuaxtla. Mexico City: Universidad Nacional Autónoma dissertation.

Hollenbach, Barbara E. 1976. Tense-negation interplay in Copala Trique. International Journal of American Linguistics 42. 126-132. https://doi.org/10.1086/465400. 
Hollenbach, Barbara E. 1984. The phonology and morphology of tone and laryngeals in Copala Trique. Tuscon, AZ: University of Arizona dissertation.

Hollenbach, Barbara E. 2004. Gramática popular del triqui de Copala. Oaxaca, MX: SIL Mexico.

Hollenbach, Barbara E. 2007. Vocabulario breve del triqui de San Juan Copala. Dallas, TX: SIL International.

Horwood, Graham. 2000. Anti-faithfulness and subtractive morphology. Ms. Rutgers University.

Hyman, Larry M. 2011. Do tones have features? In John A. Goldsmith, Elizabeth V. Hume \& Leo Wetzels (eds.), Tones and features: Phonetic and phonological perspectives (Studies in Generative Grammar 107). 50-80. Berlin: De Gruyter. https://doi.org/10.1515/9783110246223.50.

Inkelas, Sharon. 2011. The interaction between morphology and phonology. In John Goldsmith, Jason Riggle \& Alan C. L. Yu (eds.), The handbook of phonological theory. 68-102. Hoboken, NJ: Blackwell Publishing. https://doi.org/10.1002/9781444343069.ch3.

Inkelas, Sharon. 2014. The interplay of morphology and phonology. Oxford: Oxford University Press. https://doi.org/10.1093/acprof:oso/9780199280476.001.0001.

Inkelas, Sharon \& Cheryl Zoll. 2007. Is grammar dependence real? A comparison between cophonological and indexed constraint approaches to morphologically conditioned phonology. Linguistics 45(1). 133171. https://doi.org/10.1515/LING.2007.004.

Kager, René. 1999. Optimality theory. Cambridge, UK: Cambridge University Press. https://doi.org/10.1017/ CBO9780511812408.

Kim, Yuni. 2016. Tonal overwriting and inflectional exponence in Amuzgo. In Enrique Palancar \& JeanLéo Léonard (eds.), Tone and inflection: New facts and new perspectives (Trends in Linguistics. Studies and Monographs [TiLSM] 296). 199-224. Berlin: De Gruyter. https://doi.org/10.1515/9783110452754-009.

Kiparsky, Paul. 1985. Some consequences of Lexical Phonology. Phonology Yearbook 2. 85-138. https://doi.org/10.1017/S0952675700000397.

Kiparsky, Paul. 2000. Opacity and cyclicity. The Linguistic Review 17.351-367. https://doi.org/ 10.1515/tlir.2000.17.2-4.351.

Kurisu, Kazutaka. 2001. The phonology of morpheme realization. Santa Cruz, CA: University of California dissertation. https://doi.org/10.1515/jj1-2002-0109.

de Lacy, Paul. 2012. Morphophonological polarity. In Jochen Trömmer (ed.), The morphology and phonology of Exponence. 121-159. Oxford: Oxford University Press. https://doi.org/10.1093/acprof:oso/9780199573721.003.0005.

Longacre, Robert E. 1952. Five phonemic pitch levels in Trique. Acta Linguistica 7. 62-81.

Longacre, Robert E. 1959. Trique Tone Morphemics. Anthropological Linguistics 1(4). 5-42.

Macaulay, Monica \& Joseph C. Salmons. 1995. The phonology of glottalization in Mixtec. International Journal of American Linguistics 61(1). 38-61. https://doi.org/10.1086/466244.

McCarthy, John J. \& Alan Prince. 1995. Faithfulness and reduplicative identity. In Jill Beckman, Laura Walsh Dickey \& Suzanne Urbanczyk (eds.), University of Massachusetts occasional papers in linguistics, vol. 18. 249-384. Amherst, MA: GLSA.

McPherson, Laura. 2017. Tone features revisited: evidence from Seenku. In Doris L. Payne, Sara Pacchiarotti \& Mokaya Bosire (eds.), Diversity in African languages. 5-22. Berlin: Language Science Press.

Miller, Amy. 2001. A grammar of Jamul Tiipay. Berlin: De Gruyter. https://doi.org/10.1515/9783110864823.

Newman, Paul. 2000. The Hausa language: An encyclopedic reference grammar. New Haven, CT: Yale University Press.

Nyman, Alexandra \& Bruce Tesar. 2019. Determining underlying presence in the learning of grammars that allow insertion and deletion. Glossa 4(1). 1-41. https://doi.org/10.5334/gjgl.603.

Odden, David. 2011. Features impinging on tone. In John A. Goldsmith, Elizabeth V. Hume \& Leo Wetzels (eds.), Tones and features: Phonetic and phonological perspectives (Studies in Generative Gra- 
mmar 107). 81-107. Berlin: De Gruyter. https://doi.org/10.1515/9783110246223.81.

Palancar, Enrique \& Jean-Léo Léonard (eds.). 2016. Tone and inflection: New facts and new perspectives (Trends in Linguistics. Studies and Monographs [TiLSM] 296). Berlin: De Gruyter.

Palancar, Enrique L., Jonathan D. Amith \& Rey Castillo García. 2016. Verbal inflection in Yoloxóchitl Mixtec. In Enrique L. Palancar \& Jean-Léo Léonard (eds.), Tone and inflection: New facts and new perspectives (Trends in Linguistics. Studies and Monographs [TiLSM] 296). 295-336. Mouton de Gruyter. https://doi.org/10.1515/9783110452754-012.

Pankratz, L. \& Eunice V. Pike. 1967. Phonology and morphotonemics of Ayutla Mixtec. International Journal of AmericanLinguistics 33(4). 287-299. https://doi.org/10.1086/464980.

Pike, Kenneth L. 1948. Tone languages. Ann Arbor, MI: University of Michigan Press.

Prince, Alan \& Paul Smolensky. 1993. Optimality theory: Constraint interaction in generative grammar (Technical Report 2 Rutgers University Center for Cognitive Science). Cambridge, MA: MIT Press.

Silverman, Daniel. 1997. Laryngeal complexity in Otomanguean vowels. Phonology 14. 235-261.

Steriade, Donca. 2000. Paradigm uniformity and the phonetics-phonology boundary. In Michael Broe \& Janet Pierrehumbert (eds.), Papers in laboratory phonology V: Acquisition and the lexicon. 313334. Cambridge, UK: Cambridge University Press.

Tesar, Bruce. 2014. Output-driven phonology: Theory and learning. Cambridge, UK: Cambridge University Press. https://doi.org/10.1017/CBO9780511740039.

Tucker, Archibald. 1994. A Grammar of Kenya Luo (Dholuo). Köln: Köppe.

Vaux, Bert. 2008. Why the phonological component must be serial and rule-based. In Bert Vaux \& Andrew Nevins (eds.), Rules, constraints, and phonological phenomena. 21-60. Oxford, UK: Oxford University Press.

Walker, Rachel. 2000. Nasal reduplication in Mbe affixation. Phonology 17. 65-115. https://doi. org/10.1017/S0952675700003833.

Westermann, Diedrich. 1912. The shilluk people: Their language and folklore. Board of Foreign Missions of the United Presbyterian Church of North America.

Wunderlich, Dieter. 2012. Polarity and constraints on paradigmatic distinctness. In Jochen Trömmer (ed.), The morphology and phonology of exponence. 160-194. Oxford, UK: Oxford University Press. https://doi.org/10.1093/acprof:oso/9780199573721.003.0006.

Yip, Moira. 1993. Tonal register in East Asian languages. In Harry Van der Hulst \& Keith Snider (eds.), The phonology of tone: The representation of tonal register. 245-268. Berlin: De Gruyter.

Yip, Moira. 2002. Tone (Cambridge Textbooks in Linguistics). Cambridge, UK: Cambridge University Press. https://doi doi.org/10.1017/CBO9781139164559.

Christian DiCanio

Department of Linguistics

University at Buffalo

609 Baldy Hall

Buffalo, NY 14260 USA

cdicanio@buffalo.edu

Benigno Cruz Martínez

Proyecto de documentación de la lengua triqui de San Martín Itunyoso

San Martín Itunyoso, Oaxaca, Mexico

cruz1302@hotmail.com
Basileo Martínez Cruz

Proyecto de documentación de la lengua

triqui de San Martín Itunyoso

San Martín Itunyoso, Oaxaca, Mexico

basi.mtz@outlook.es

Wilberto Martínez Cruz

Proyecto de documentación de la lengua

triqui de San Martín Itunyoso

San Martín Itunyoso, Oaxaca, Mexico

wilber.smi@gmail.com 